\title{
Transcription factors Tp73, Cebpd, Pax6, and Spi1 rather than DNA methylation regulate chronic transcriptomics changes after experimental traumatic brain injury
}

Anssi Lipponen ${ }^{1}$, Assam El-Osta ${ }^{2,3}$, Antony Kaspi ${ }^{2}$, Mark Ziemann², Ishant Khurana², Harikrishnan KN², Vicente Navarro-Ferrandis ${ }^{1}$, Noora Puhakka', Jussi Paananen ${ }^{4,5}$ and Asla Pitkänen ${ }^{1 *}$

\begin{abstract}
Traumatic brain injury (TBI) induces a wide variety of cellular and molecular changes that can continue for days to weeks to months, leading to functional impairments. Currently, there are no pharmacotherapies in clinical use that favorably modify the post-TBI outcome, due in part to limited understanding of the mechanisms of TBI-induced pathologies. Our system biology analysis tested the hypothesis that chronic transcriptomics changes induced by TBI are controlled by altered DNA-methylation in gene promoter areas or by transcription factors. We performed genome-wide methyl binding domain (MBD)-sequencing (seq) and RNA-seq in perilesional, thalamic, and hippocampal tissue sampled at 3 months after TBI induced by lateral fluid percussion in adult male Sprague-Dawley rats. We investigated the regulated molecular networks and mechanisms underlying the chronic regulation, particularly DNA methylation and transcription factors. Finally, we identified compounds that modulate the transcriptomics changes and could be repurposed to improve recovery. Unexpectedly, DNA methylation was not a major regulator of chronic post-TBI transcriptomics changes. On the other hand, the transcription factors Cebpd, Pax6, Spi1, and Tp73 were upregulated at 3 months after TBI (False discovery rate $<0.05$ ), which was validated using digital droplet polymerase chain reaction. Transcription regulatory network analysis revealed that these transcription factors regulate apoptosis, inflammation, and microglia, which are well-known contributors to secondary damage after TBI. Library of Integrated Network-based Cellular Signatures (LINCS) analysis identified 118 pharmacotherapies that regulate the expression of Cebpd, Pax6, Spi1, and Tp73. Of these, the antidepressant and/or antipsychotic compounds trimipramine, rolipramine, fluspirilene, and chlorpromazine, as well as the anti-cancer therapies pimasertib, tamoxifen, and vorinostat were strong regulators of the identified transcription factors, suggesting their potential to modulate the regulated transcriptomics networks to improve post-TBI recovery.
\end{abstract}

Keywords: DNA methylation, LINCS analysis, MBD-seq, Recovery, RNA-seq, Treatment

\section{Introduction}

Every year, 2.5 million people in Europe and the USA sustain traumatic brain injury (TBI) $[15,28,74]$. TBI is a major cause of disability and death in patients younger than 45 years of age [65]. Despite a large number of preclinical and clinical studies, an effective pharmacotherapy

\footnotetext{
* Correspondence: asla.pitkanen@uef.fi

${ }^{1}$ Epilepsy Research Laboratory, A. I. Virtanen Institute for Molecular Sciences, University of Eastern Finland, PO Box 1627, FIN-70211 Kuopio, Finland Full list of author information is available at the end of the article
}

to improve post-TBI outcome is still lacking $[22,25,76]$. This is due in part to the complexity of the secondary pathologies induced by TBI, including neurodegeneration, inflammation, oxidative stress, axonal and myelin injury, and vascular changes $[64,79,80]$. These pathologies progress in parallel and serial time windows over weeks to months in experimental models $[7,46,91,112]$ and humans $[36,49,98]$. As these observations suggest complex and long-lasting transcriptomics regulation, we propose that a network therapy rather than a 
monotherapy approach will be more effective for repair of the ongoing damage.

To date, a number of studies have investigated transcriptomics changes at a genome-wide scale at 24-48 $\mathrm{h}$ after TBI $[14,17,38,42,47,48,59,63,78,85,97,99,104$, $122,123,125,128-130,136]$. Of these 19 genome-wide gene expression studies, 11 report dysregulation of transcription factors in the acute post-TBI phase [17, 48, 59, 78, 85, 97, 104, 123, 128-130]. Four hypothesis-driven analyses focusing on individual transcription factors report the dysregulation of Jun [133], Cebpd [105], Runx1 [70], and Olig2 [9] in the acute post-TBI phase. Most of the studies, however, analyzed only acute post-TBI timepoints and a single brain area, typically the hippocampus or cortex. Further, very few studies have explored the mechanisms that regulate post-TBI gene expression, such as genome-wide DNA methylation [20,39, 83].

We hypothesized that TBI results in chronic transcriptomics changes that are controlled by DNAmethylation changes in the gene promoter areas or by transcription factors. To test this, we induced TBI in rats by lateral fluid-percussion, and subjected the perilesional cortex, ipsilateral thalamus, and ipsilateral hippocampus to MBD-seq and RNA-seq. As bioinformatics analysis and laboratory validation indicated that transcription factors rather than DNA methylation regulate chronic transcriptomics changes, we further conducted LINCS analysis to identify compounds that regulate gene expression of these transcription factors and could therefore be repurposed to improve post-TBI outcome via transcription factor-mediated mechanisms.

\section{Materials and methods}

\section{Animals}

TBI was induced by lateral fluid-percussion injury (FPI) with an impact pressure of $3.30 \pm 0.01$ atm in 14 adult male Sprague-Dawley rats (330-370 g at the time of TBI or sham operation; Harlan, The Netherlands) as previously described [54, 81]. Eleven sham-operated animals served as experimental controls. At 3 months after TBI, the perilesional cortex, thalamus, and hippocampus were collected as described in Lipponen et al. [69]. Briefly, the rats were anesthetized with $5 \%$ isoflurane and decapitated. The brain was removed from the skull, flushed with $0.9 \%$ cold $\left(4{ }^{\circ} \mathrm{C}\right)$ sodium chloride, and placed onto a slicing matrix on ice (\#15007, Rodent Brain Matrix, Ted Pella, Inc., Redding, CA, USA). Two 2-mm-thick coronal slices were cut (between -2.2 and -6.2 from the bregma), from which the perilesional cortex, ipsilateral thalamus, and ipsilateral hippocampus (including dentate gyrus) were dissected on top of the light table under the magnifying glass. Brain tissue samples were snap-frozen in liquid nitrogen, and stored at $-70{ }^{\circ} \mathrm{C}$ until RNA and DNA extraction.
All animal operations were approved by The Animal Ethics Committee of the Provincial Government of Southern Finland and carried out according to the guidelines of the European Community Council Directives 2010/63/EU.

\section{Preparation of MBD- and RNA-seq libraries and sequencing DNA and RNA extraction}

Brain tissue from five TBI and five sham-operated rats was used for methyl-binding domain sequencing (MBDseq) and RNA-sequencing (RNA-seq). DNA and RNA were co-purified from the perilesional cortex, ipsilateral hippocampus, or ipsilateral thalamus using a DNeasy Blood\&Tissue kit (\#69504, Qiagen, Hilden, Germany). Quality control of the total RNA was performed using a MultiNA electrophoresis device (Shimazu, Kyoto, Japan).

\section{RNA-seq library and sequencing}

The mRNA library preparation and RNA-sequencing were performed as described in Lipponen et al. [69]. Briefly, mRNA was enriched using Dynabeads Oligo (dT) 25 beads (\#61002, Invitrogen, Carlsbad, CA, USA), and the sequencing libraries were compiled with the NEBNext mRNA Library Prep Reagent Set (\#E6100S, New England Biolabs, Ipswich, MA, USA). Quality control of the sequencing libraries was performed with a MultiNA electrophoresis device (Shimazu, Kyoto, Japan). Sequencing of the mRNA libraries for the perilesional cortex and hippocampus was carried out with an Illumina Genome Analyzer IIx (San Diego, CA, USA), and for the thalamus using an Illumina HiSeq 2000 (San Diego, CA, USA). The Illumina Off-Line Basecaller v1.8 was used for base-calling. RNA-seq raw data can be downloaded from the NCBI Gene Expression Omnibus (GEO; series accession number GSE80174).

\section{$M B D$-seq library and sequencing}

For MBD-seq, $2 \mu \mathrm{g}$ of DNA was fragmented by sonication, and the quality was controlled with a MultiNA electrophoresis device (Shimazu, Kyoto, Japan). Methylated DNA was enriched with a 2-M sodium chloride elution using MethylMiner ${ }^{\mathrm{m}} k$ kit (Thermo Fischer Scientific, Waltham, MA, USA), and quantified using a Qubit fluorometer (Thermo FisherScientific, Waltham, MA, USA). The sequencing library was prepared from $5 \mathrm{ng}$ of enriched methylated DNA using an NEB Next DNA library kit (\#E6040S, New England Biolabs, Ipswich, MA, USA). Then, MBD-sequencing and base-calling for the perilesional cortex, hippocampus, and thalamus were carried out as described above. Raw MBD-seq data was saved to the NCBI Gene Expression Omnibus (GEO; series accession number GSE107837). 


\section{Mapping of sequencing data, and identification of differentially methylated regions and differentially expressing genes \\ Methylation}

Quality control of the MBD-sequencing raw reads was performed using FastQC [3]. Sequencing raw reads were mapped to the Ensemble RN5 genome with Spliced Transcripts Alignment to a Reference (STAR) software (version 2.3.0e_r291) [24] with parameter alignIntronMax 1 to prohibit splicing and allow genomic mapping. The mapping percentages were $71.2 \pm 4.0 \%$ for the perilesional cortex, $63.3 \pm 3.2 \%$ for the ipsilateral hippocampus, and $71.3 \pm 2.7 \%$ for the ipsilateral thalamus. Differentially-methylated gene promoters (5000 bp upstream and $200 \mathrm{bp}$ downstream from the transcription start site), exons, and gene body area were identified with blocksStats function in the Repitools 1.21.1 R package [115] with $\mathrm{R}$ version 3.1.0. The adjusted $p$-value was calculated with a Benjamini-Hochberg false discovery rate (FDR). DNA methylation was considered significantly changed if the FDR was $<0.05$.

\section{Gene expression}

RNA-seq quality control, mapping, and identification of differentially expressed genes were previously described in detail (Lipponen et al. 2016) [69]. Shortly, quality control of the RNA-seq reads was performed using FastQC [3] and reads were aligned to the Ensemble RN5 genome with STAR software (version 2.3.0e_r291) [24]. Differentially expressed genes were identified with DEseq2 [72] $R$ package ( $R$ version 3.1.0) and the Benjamini-Hochberg false discovery rate (FDR) was used to calculate the adjusted $p$-value. Gene expression was considered to be significantly differentially expressed when FDR $<0.05$.

Effect of DNA methylation in the promoter, exon, or gene body region on gene expression

\section{Gene set enrichment analysis}

To analyze the effect of DNA methylation located in the gene promoter, exon, or gene body areas on gene expression, we performed Gene Set Enrichment Analysis (GSEA) [116]. First, we prepared ranked lists from the gene expression data in the perilesional cortex, hippocampus, and thalamus by ranking the genes in order according to the p-value of mRNA differential expression. Upregulated genes were assigned with a positive rank number and downregulated genes with a negative rank number. Then, we generated three gene sets (genes with differentially methylated promoters, exons, or gene body areas) from each of the three brain areas (perilesional cortex, hippocampus, thalamus). Enrichment of these sets within the ranked lists was studied using GSEA, and enrichment was considered significant when the FDR qvalue was $<0.05$.

\section{Linear regression analysis}

To confirm the GSEA results, we analyzed the association of DNA methylation in the gene promoter, exon, and gene body areas on gene expression using two different linear regression models: (a) association of DNA methylation on gene expression, (b) association of TBI on gene expression via DNA methylation. Regression analysis was carried out with $\mathrm{lm}$-function in $\mathrm{R}$ v3.1.0. Genes with average mRNA read number $<50$ were filtered out from the analysis. Regression was considered significant when FDR $<0.05$.

\section{Validation of gene promoter methylation and gene expression}

Digital droplet polymerase chain reaction (ddPCR) and pyrosequencing were used to confirm the gene expression changes in the RNA-seq and the methylation changes in the MBD-seq, respectively, of the four top hits. Of the four top hits, Gpr12 and $\mathbf{L r p 1 b}$ were downregulated in the mRNA-seq and showed increased promoter methylation in the MBD-seq in the perilesional cortex, Ppid showed increased promoter methylation in the thalamus, and $\boldsymbol{W d r} \mathbf{2 6}$ showed increased promoter methylation in the hippocampus (Table 1).

Table 1 Gene promoter methylation and gene expression of Wdr26, Lrp16, Ppid and Gpr12 in perilesional cortex, hippocampus and ipsilateral thalamus according MBD and RNA-seq

\begin{tabular}{|c|c|c|c|c|c|}
\hline & & Wdr26 & Lrpib & Ppid & Gpr12 \\
\hline \multirow[t]{6}{*}{ Perilesional Cx } & \multicolumn{5}{|c|}{ Gene expression } \\
\hline & $\log 2 \mathrm{FC}$ & -0.161 & -0.441 & -0.222 & -0.531 \\
\hline & FDR & 0.300607 & 0.022273 & 0.242403 & 0.000197 \\
\hline & \multicolumn{5}{|c|}{ Methylation } \\
\hline & $\log 2 \mathrm{FC}$ & 0.313 & 1.402 & 0.038 & 1.407 \\
\hline & FDR & 1 & 0.01901 & 1 & 0.014662 \\
\hline \multirow[t]{6}{*}{ Hippocampus } & \multicolumn{5}{|c|}{ Gene expression } \\
\hline & $\log 2 \mathrm{FC}$ & -0.129 & -0.166 & -0.036 & 0.224 \\
\hline & FDR & 0.999825 & 0.999825 & 0.999825 & 0.999825 \\
\hline & \multicolumn{5}{|c|}{ Methylation } \\
\hline & $\log 2 \mathrm{FC}$ & 2.660 & -0.602 & 1.930 & 0.179 \\
\hline & FDR & $1.87 \mathrm{E}-14$ & 1 & $1.4 \mathrm{E}-07$ & 1 \\
\hline \multirow[t]{6}{*}{ Thalamus } & \multicolumn{5}{|c|}{ Gene expression } \\
\hline & $\log 2 \mathrm{FC}$ & 0.140 & -0.097 & -0.074 & -0.687 \\
\hline & FDR & 0.721246 & 0.795279 & 0.873954 & 0.000388 \\
\hline & \multicolumn{5}{|c|}{ Methylation } \\
\hline & $\log 2 \mathrm{FC}$ & 0.241 & 0.159 & 0.059 & -0.014 \\
\hline & FDR & 1 & 1 & 1 & 1 \\
\hline
\end{tabular}

Abbreviations: $C x$ perilesional cortex, $F C$ fold-change. Statistical significances: $\log 2 \mathrm{FC}$ change and corresponding FDR $(<0.05)$ are shown in bolded font 


\section{Extraction of RNA for ddPCR and DNA for pyrosequencing}

Brain tissue from nine TBI and six sham-operated animals was collected as described above. The animals belonged to the same cohort of injured rats used for the RNA-seq and MBD-seq analyses.

RNA and DNA were extracted simultaneously from the perilesional cortex, thalamus, or hippocampus using a mirVana miRNA isolation kit (\#AM1560, Life Technologies (Ambion) Carlsbad, CA, USA), QIAshredder (\#79654, Qiagen), and AllPrep DNA/RNA Mini Kit (\#80204, Qiagen) as previously described [90]. Briefly, to avoid clogging the spin columns, brain tissue was divided into $2-5$ pieces (each $\sim 10 \mathrm{mg}$ ) on dry ice. Each tissue piece was then placed into a $2-\mathrm{ml}$ microcentrifuge tube together with one metal ball and $800 \mu \mathrm{l}$ of Ambion Lysis/binding buffer, and homogenized with a TissueLyser (Qiagen) for $3 \mathrm{~min}(30 \mathrm{~Hz})$. For further homogenization, the lysate was transferred to a QIAshedder spin column and centrifuged $(16,000 \mathrm{~g})$ for $2 \mathrm{~min}$ at $4{ }^{\circ} \mathrm{C}$. Flow-through lysate was transferred back to the QIAshedder spin column and centrifuged again. For DNA extraction, lysate was transferred to a Qiagen All Prep DNA spin column and centrifuged $(10,000 \mathrm{~g})$ for $1 \mathrm{~min}$ at room temperature. The spin-column was washed and eluted according to the instructions provided in the AllPrep DNA/RNA Mini Kit for DNA extraction.

Flow-through from the All Prep DNA spin column was used for RNA extraction using a mirVana miRNA isolation kit. Briefly, miRNA homogenate additive $(70 \mu \mathrm{l})$ was added to the flow-through. The mixture was vigorously vortexed for $30 \mathrm{~s}$ and then incubated on ice for $10 \mathrm{~min}$. Acid-phenol:chloroform $(700 \mu \mathrm{l})$ was then added, mixed, and centrifuged $(16,000 \mathrm{~g})$ for $30 \mathrm{~s}$. The aqueous upper phase was transferred to a new microcentrifuge tube. Five hundred microliters of water was added to the lower phase, mixed, and centrifuged $(16,000 \mathrm{~g})$ for $30 \mathrm{~s}$. The upper aqueous phase was collected into the same tube as the aqueous phase from the previous extraction cycle. Then, $100 \%$ ethanol $(625 \mu \mathrm{l})$ was added to the tube, mixed, and transferred to the mirVana miRNA isolation spin column. Finally, RNA was washed and eluted from the spin column according to instructions provided with the mirVana miRNA isolation kit. Finally, RNA extracted from each brain region was pooled.

\section{Pyrosequencing}

Percentage (ratio of methylated/nonmethylated DNA * 100) of DNA methylated cytosines at a given CpG site in the Ppid, Lrp1b, or Wrd26 gene promoters, or at two CpG sites in the Gpr12 promoter was measured with pyrosequencing using the PSQ 96MA 2.1 platform (Biotage AB, Uppsala, Sweden) in the Genome Center of the
University of London (Additional file 1). The MannWhitney $U$ test was used to assess the significance of the difference in the percentage of methylation between the TBI and sham-operated animals $(p<0.05$ was considered statistically significant) (Table 2).

\section{$d d P C R$}

RNA quality was checked with a 2100 Bioanalyzer (Agilent, Santa Clara, CA, USA) and RNA 6000 Nano Kit (\#5067-1511, Agilent). The RNA integrity number (RIN) was $>8.0$ in all but one sample (RIN 7.8). Therefore, $50 \mathrm{ng}$ of RNA from all 15 samples was translated to cDNA using an iScript Advanced cDNA synthesis kit (\#172-5038, BioRad, Hercules, CA, USA). Gene expression of Ppid, Gpr12, Lrp1b, and Wrd26 was validated by ddPCR using $\boldsymbol{A c t} \boldsymbol{b}$ as a reference gene. ddPCR was conducted using QX200 ddPCR EvaGreen Supermix solution (\#186-4033, BioRad) and a PrimerPCR gene expression assay (Actb; \#dRnoEG5146006, Gpr12; \#dRnoEG5125945, Lrp1b; \#dRnoEG5140109, Ppid; \#dRnoEG5125166, Wdr26; \#dRnoEG5145659, BioRad) according to the manufacturer's instructions. Droplets were generated and their fluorescence measured with a QX200 Droplet Digital PCR System (BioRad). Fluorescent droplets were classified as "positive" and "negative", and then the concentration of each gene (copy/ $\mu \mathrm{l})$ was calculated using QuantaSoft 1.7.4 (BioRad). Target gene concentrations were normalized according to the Actb reference gene, $\log 2$ fold-changes were calculated, and the significance in the difference in droplet counts between the TBI and sham-operated rats was assessed using the Mann-Whitney U test (Table 2).

\section{Identification of transcription factors that chronically regulate post-TBI transcriptomics \\ Transcription regulatory network of the perilesional cortex and ipsilateral thalamus}

To analyze the regulation of post-TBI transcriptomics by transcription factors in the perilesional cortex and ipsilateral thalamus, and to further visualize their target genes, we downloaded the transcription regulatory network (TRN) from the SignaLink 2.0 database [31, 60]. Then, RNA-seq data from both brain areas (fold-change and FDR between sham-operated experimental controls and TBI animals) was integrated with the SignaLink 2.0 TRN in Cytoscape 3.4 [108]. To visualize the regulated targets of each selected transcription factor, differentially expressed transcription factors in mRNA-seq (FDR < 0.05 and $\log 2 \mathrm{FC}<-1$ or $>1$ ) and their nearest downstream neighbors in the TRN were detached from the SignaLink 2.0 network. Further analysis focused on the four transcription factors that had the highest number of regulated target genes in TRN. 
Table 2 Validation of gene promoter methylation by pyrosequencing and gene expression by ddPCR in the perilesional cortex, thalamus and hippocampus. As negative controls, we also assessed the methylation and gene expression in the ipsilateral hippocampus and thalamus. Wdr26, Lrp16, and Ppid genes had only one CpG site whereas Gpr12 gene had two CpG sites

\begin{tabular}{|c|c|c|c|c|c|c|}
\hline & & Wdr26 & Lrplb & Ppid & Gpr12 & \\
\hline \multirow[t]{7}{*}{ Perilesional $C x$} & Gene expression & & & & & \\
\hline & $\log 2 F C$ & -0.94944 & -0.17498 & -0.60015 & \multicolumn{2}{|c|}{-0.37159} \\
\hline & $\mathrm{p}$-value & 0.007592 & 0.7756 & 0.03596 & \multicolumn{2}{|c|}{0.3277} \\
\hline & \multicolumn{6}{|l|}{ Methylation } \\
\hline & Average methylation (\%) & 85.31 & 67.28 & 59.52 & CpG site1: 73.43 & CpG site2: 76.57 \\
\hline & Difference TBI - sham (\%) & 1.07 & -0.17 & 2.39 & CpG site1:0.43 & CpG site2:0.35 \\
\hline & p-value & 0.1135 & 0.9546 & 0.3636 & CpG site1: 0.8639 & CpG site2: 1 \\
\hline \multirow[t]{7}{*}{ Hippocampus } & Gene expression & & & & & \\
\hline & $\log 2 \mathrm{FC}$ & -0.6746 & -0.6457 & -1.3397 & \multicolumn{2}{|c|}{-0.3415} \\
\hline & $\mathrm{p}$-value & 0.366 & 0.1375 & 0.366 & \multicolumn{2}{|c|}{0.366} \\
\hline & \multicolumn{6}{|l|}{ Methylation } \\
\hline & Average methylation (\%) & 87.22 & 59.92 & 57.25 & CpG site1: 69.06 & CpG site2: 73.48 \\
\hline & Difference TBI - sham (\%) & 1.10 & -2.73 & 2.65 & CpG site1: 1.70 & CpG site2: -0.59 \\
\hline & $\mathrm{p}$-value & 0.366 & 0.2343 & 0.366 & CpG site1: 0.5338 & CpG site2: 1 \\
\hline \multirow[t]{7}{*}{ Thalamus } & Gene expression & & & & & \\
\hline & $\log 2 F C$ & -0.8936 & -0.4964 & -0.9309 & \multicolumn{2}{|c|}{-1.3735} \\
\hline & $p$-value & 0.181 & 0.3277 & 0.06633 & \multicolumn{2}{|c|}{0.001598} \\
\hline & \multicolumn{6}{|l|}{ Methylation } \\
\hline & Average methylation (\%) & 85.11 & 65.82 & 49.95 & CpG site1: 74.23 & CpG site2: 77.40 \\
\hline & Difference TBI - sham (\%) & 1.07 & -2.33 & 7.69 & CpG site1: -0.95 & CpG site2: -0.93 \\
\hline & p-value & 0.1469 & 0.5287 & 0.3884 & CpG site1: 0.7756 & CpG site2: 0.1135 \\
\hline
\end{tabular}

Abbreviations: CX cortex, FC fold-change. Statistical significances: log2FC change and corresponding $\mathrm{p}$-value $(<0.05)$ are shown in bolded font

\section{Validation of gene expression of the top four transcription factors ddPCR}

Digital droplet PCR of the four top transcription factors (Cebpd, Pax6, Spi1, and Tp73) using Actb as a reference gene was performed to confirm the change in the expression of transcription factors coding genes. Analysis was performed using the same RNA samples, cDNA synthesis method, and ddPCR EvaGreen Supermix solution as for the validation of MBD-seq data (see above). A PrimerPCR gene expression assay (Actb; \#dRnoEG5146006, Cebpd; \#dRnoEG5126239, Pax6; \#dRnoEG5125771, Spi1; \#dRnoEG5139059, Tp73; \#dRnoEG5139860, BioRad) was performed according to the manufacturer's instructions. Droplets were generated and their fluorescence measured with the QX200 Droplet Digital PCR System. QuantaSoft 1.7.4 was used to classify droplets as "positive" and "negative", and to calculate the concentration of gene copies/ $\mu \mathrm{l}$ as described earlier. Finally, the target gene concentration was normalized with the reference gene concentration, the log2 fold-change of the concentration was calculated, and the significance in the difference in concentrations between the TBI and sham-operated rats was assessed using the Mann-Whitney U test.
Identification of compounds modifying the transcription factor gene expression with the LINCS database Compounds modifying transcription factors gene expression Next, we searched the LINCS database (http://data.lincscloud.org.s3.amazonaws.com/index.html) to identify compounds that modify the expression of the four top transcription factors revealed by the SignaLink 2.0 database analysis. An in-housecreated R script was used to run LINCS through an application programming interface. Reproducible compound-induced transcriptomics changes in terminally differentiated neurons (NEU), terminally differentiated neurons treated with $\mathrm{KCl}$ (NEU.KCL), and induced pluripotent stem cells-derived neural progenitor cells (NPC) were included in the analysis. As a result, we obtained a list of compounds that modulated the expression of transcription factors in one to three cell lines (i.e., transcription factors were within the 100 most upregulated or 100 most downregulated genes by a given compound).

\section{Results}

TBI-induced gene expression changes after TBI were most prominent in the perilesional cortex and were associated with DNA methylation at the gene promoter region GSEA analysis of MBD-seq data

GSEA analysis of the perilesional cortex MBD-seq data suggested that altered DNA methylation in the gene 


\section{a perilesional cortex}

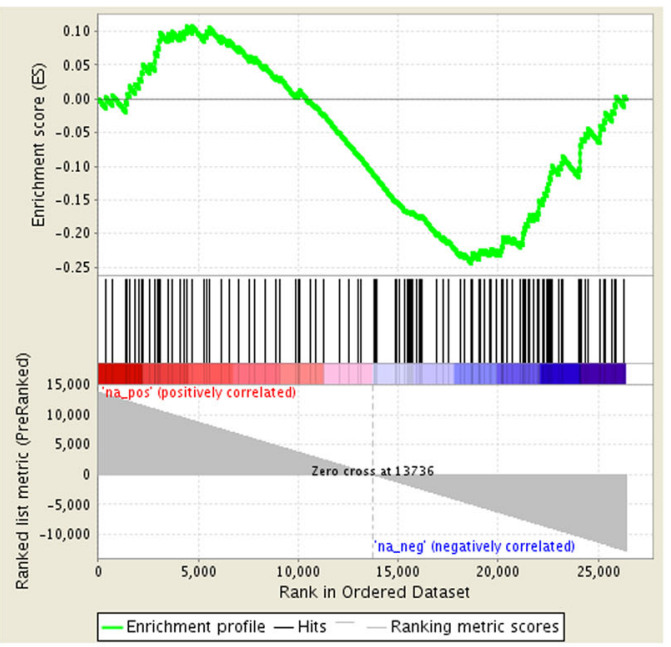

b hippocampus

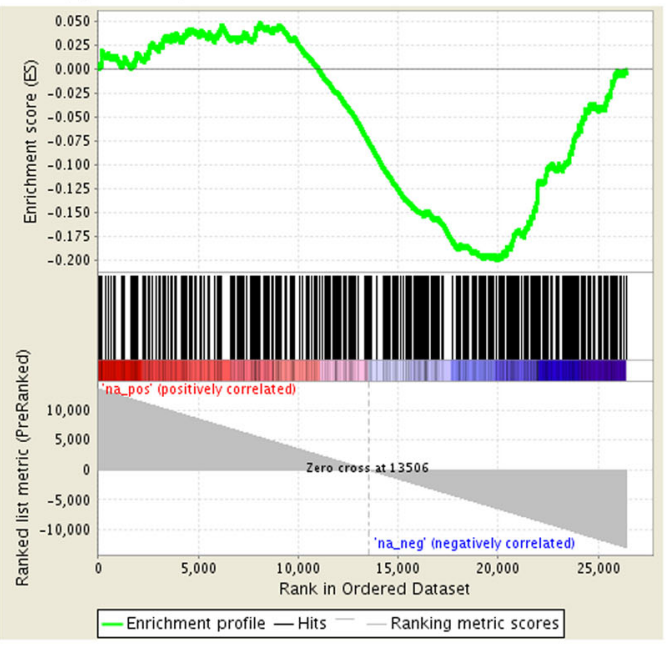

\section{C thalamus}

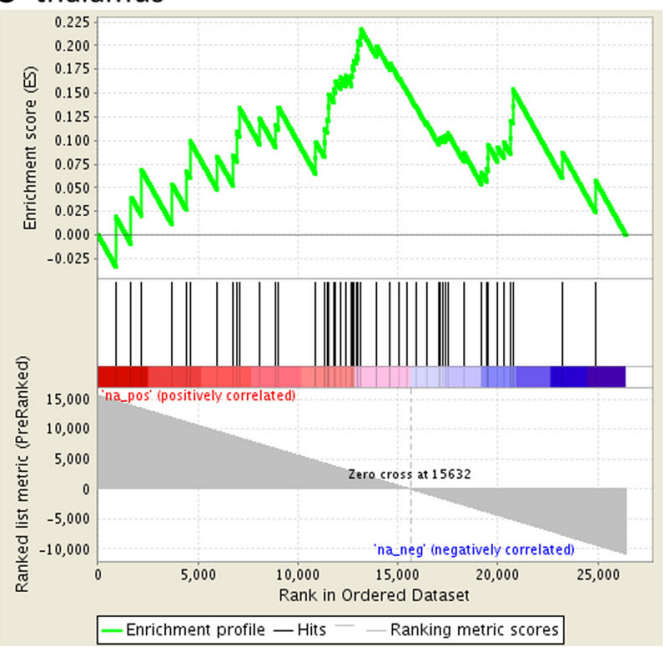

Fig. 1 Enrichment scores of Gene Set Enrichment Analysis (GSEA) of DNA methylation in gene promoters in the (a) perilesional cortex (b) ipsilateral hippocampus, and (c) ipsilateral thalamus at 3 months after TBI. GSEA indicated significant negative enrichment in the perilesional cortex (FDR q-val. 0.046), but not in the ipsilateral hippocampus (FDR q-val. 0.079) or ipsilateral thalamus (FDR q-val. 0.828)

promoter area was inversely associated with the global gene expression profile (FDR q-val. 0.046) (Fig. 1). Altered DNA methylation in the gene promoter area in the hippocampal (FDR q-val. 0.079) or thalamic samples (FDR q-val. 0.828), however, was not associated with regulated gene expression. Interestingly, changes in DNA methylation in exons were not associated with gene expression in the perilesional cortex (FDR q-val. 0.243), hippocampus (FDR q-val. 0.464), or thalamus (FDR q-val. 0.372). DNA methylation in the gene body area also was not associated with transcriptomics changes in the perilesional cortex (FDR q-val. 0.083), thalamus (FDR q-val. 0.256), or hippocampus (FDR qval. 0.631).

\section{Linear regression analysis of the MBD-seq data}

To find individual genes affected by DNA methylation and TBI from the global DNA methylation profile, we performed a regression analysis to separately assess the TBI effect and methylation effect on gene expression. In the perilesional cortex and ipsilateral thalamus, however, we observed no TBI-induced effect on DNA methylation of individual genes when the gene promoter, exon, or gene body areas were analyzed separately. In contrast, in the hippocampus, TBI affected the DNA methylation of Crybg3 (FDR $=0.0347$, estimate $=-1.105 \quad(95 \%$ confidence interval [CI]: -1.2517 to -0.9598$)$ and Mak16 $(\mathrm{FDR}=0.0356$, estimate $=4.596, \quad 95 \%$ CI: 3.9705 to 5.2219) promoters, which affected their target gene expression. in the hippocampus, no TBI effect on methylation was detected in the exon and gene body regions.

We also used regression analysis to investigate the DNA methylation effect on gene expression. DNA methylation in any of the genomic areas did not appear to affect gene expression in any of the studied brain regions.

\section{Methylation of the promoter area}

Analysis of MBD-seq data revealed significantly regulated DNA methylation in the promoter regions of 29 genes (all with increased methylation) in the perilesional cortex (FDR < 0.05). In four of 29 genes (RGD1566265, Nap1l2, Lrp1b, and Gpr12), an increase in promoter methylation was associated with reduced gene expression in the corresponding perilesional cortex (FDR $<0.05)$. In the hippocampus, none of the 166 methylation changes (97 increased and 69 decreased) in the promoter area were 
associated with changes in gene expression. In the thalamus, no alterations in promoter methylation were found $(\mathrm{FDR}<0.05)$.

\section{Methylation of exons}

Methylation in exons of 20 genes (15 increased and 5 decreased) was regulated in the hippocampus, but none of the methylation changes were associated with altered expression of the corresponding gene in the RNA-seq data (FDR < 0.05). In the perilesional cortex and thalamus, we observed no changes in exon methylation $(\mathrm{FDR}<0.05)$.

\section{Methylation of gene body areas}

Methylation of the gene body area was not changed in any of the brain areas studied (FDR $<0.05$ ).

Validation of MBD-seq using pyrosequencing and RNAseq data using ddPCR failed to confirm a link between promoter methylation and changed gene expression in the perilesional cortex at $\mathbf{3}$ months after TBI

Validation of gene promoter area methylation and gene expression

Promoter methylation and expression of Lrp1b, Gpr12, Wrd26, and Ppid genes in the perilesional cortex were validated with pyrosequencing and $\mathrm{ddPCR}$, respectively, in animals from the same cohort used for the RNA-seq and MBD-seq studies (Table 2). The percentage of methylation per CpG site in the promoter region varied from 49.95 to $87.22 \%$, depending on the gene or the methylation site in each gene (Table 2). Unexpectedly, pyrosequencing indicated that none of the four tested genes in the perilesional cortex had altered methylation in the gene promoter area (Table 2). ddPCR, however, confirmed reduced expression of $\mathbf{W r d} 26$ and Ppid in the perilesional cortex (Table 2).

Post-TBI perilesional cortex showed a substantial increase in the expression of four transcription factors Transcription factors regulating post-TBI gene expression As we observed few methylation changes in relation to the large number of transcriptomic changes in the perilesional cortex and ipsilateral thalamus, we next assessed whether chronic post-TBI regulation of gene expression in these brain areas was controlled by transcription factors. To assess whether the transcriptomic changes observed in RNA-seq correspond to alterations in local cell populations we correlated the read counts of transcription factors with the read counts of neuronal, microglial and astroglial markers (Additional files 2 and 3).

Transcription regulatory network of the perilesional cortex In the perilesional cortex, integration of SignaLink 2.0 TRN and RNA-seq revealed increased expression in five transcription factors, $\operatorname{Pax6}$ (Fig. 2), Tp73 (Fig. 3), Cebpd, Spil, and $M y b$, and decreased expression in Etv4 at 3 months post-TBI (Table 3). Pax6 had 300 targets in the TRN analysis, of which 32 were upregulated and 59 downregulated. $\boldsymbol{T p} 73$ had 54 targets in the TRN analysis, of which five were upregulated and 11 downregulated. Igfl, the only target of Cebpd, was upregulated in the TRN analysis. Spi1 had three targets in the TRN analysis, of which only $\mathbf{L s p} \mathbf{1}$ was upregulated. According to the TRN analysis, Etv 4 had one target, which did not show altered gene expression. In the TRN analysis, $\boldsymbol{M} \boldsymbol{y} \boldsymbol{b}$ had three targets, none of which showed altered expression in the perilesional cortex.

\section{Validation of transcription factor expression in the perilesional cortex after TBI}

In the perilesional cortex, validation confirmed a significant increase in gene expression of Cebpd $(p=$ 0.0003996), Pax6 ( $p=0.004795)$, Spi1 $(p=0.007592)$, and Tp73 $(p=0.0007992)$ (Table 4) at 3 months after TBI.

Transcription regulatory network of the ipsilateral thalamus TRN analysis of the ipsilateral thalamus revealed upregulation of Pax6, Cebpd, and Spi1, and downregulation of the Etv 4 transcription factor at 3 months post-TBI (Table 3). Pax6 had 19 targets that were upregulated and 14 targets that were downregulated. Igf1, the only target of Cebpd, was upregulated. Spi1 had one upregulated target, Lsp1. Etv4 showed no alteration in gene expression.

\section{Validation of transcription factor expression in the ipsilateral thalamus and hippocampus after TBI}

In the ipsilateral thalamus, validation of gene expression indicated a trend toward increased expression of Spi1 ( $p=$ 0.06633), but not Cebpd ( $p=0.2721)$, Pax6 ( $P=0.4559)$, or $\operatorname{Tp} 73(p=0.3884)$ (Table 4) at 3 months after TBI. In the ipsilateral hippocampus, gene expression was unchanged.

LINCS analysis revealed 118 candidate pharmacotherapies that can regulate transcription factors

Pharmacotherapies regulating transcription factor gene expression

The LINCS database analysis revealed 118 pharmacotherapies that can modify the gene expression of the top four transcription factors (Pax6, Tp 73, Cebpd, and Spi1) (Table 5). Expression of Cebpd was upregulated by 92 compounds and downregulated by two compounds. Pax6 was upregulated by eight compounds and downregulated by six compounds. Spi1 was upregulated by two compounds and downregulated by three compounds. Tp73 was upregulated by five compounds. Interestingly, none of the compounds regulated more than one transcription factor. 


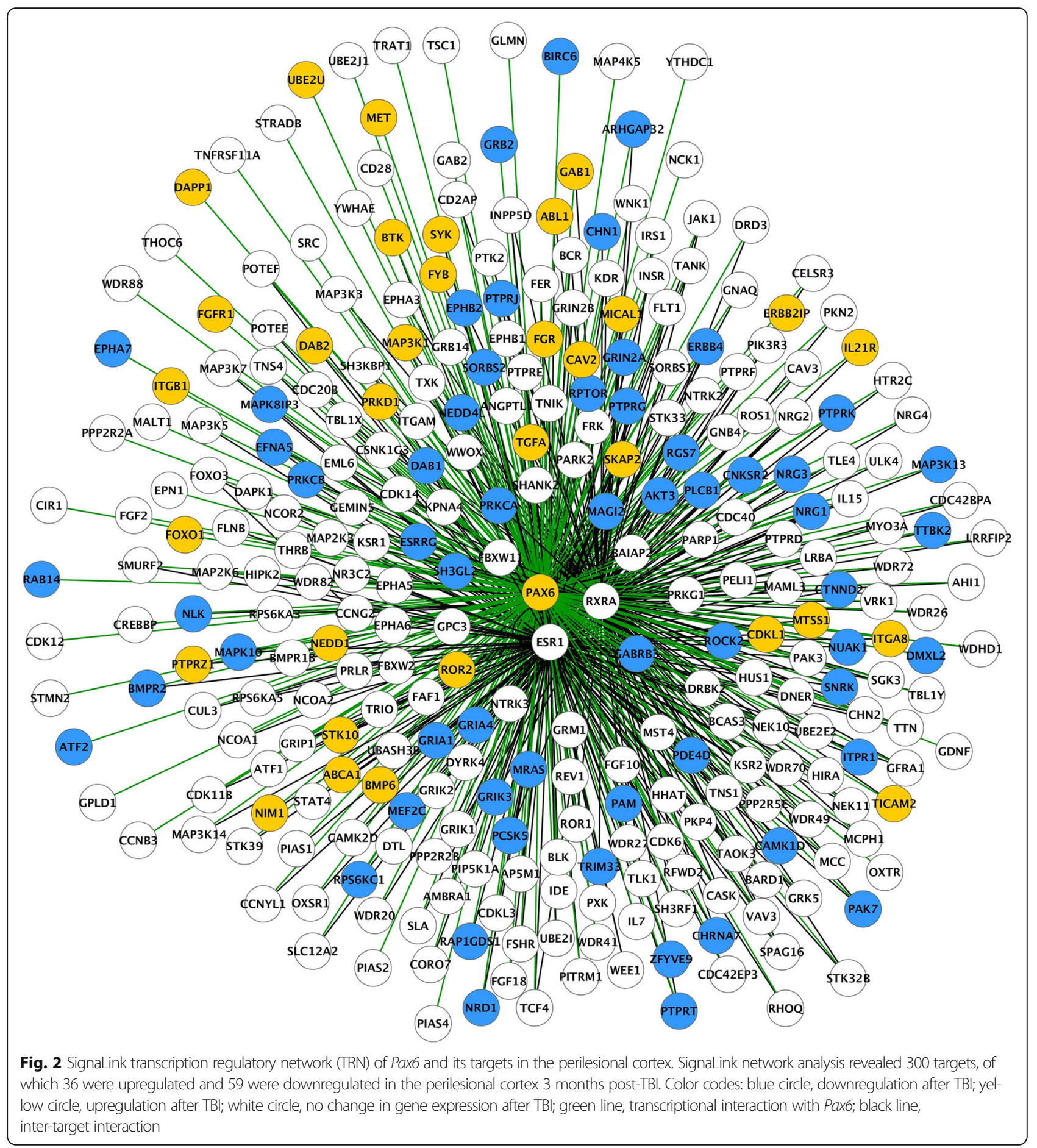

\section{Discussion}

In the present study, we evaluated whether TBI induces long-lasting transcriptomics regulation that is under the control of DNA-methylation. Bioinformatics analysis indicated that transcription factors rather than DNA methylation regulate gene expression at 3 months after TBI. Further, LINCS analysis revealed that several drugs already in clinical use modulate the expression of the identified key regulatory transcription factors Cebpd, Pax6, Spi1, and Tp73.

DNA methylation is not a major regulator of chronically altered post-TBI gene expression in our experimental model

Our previous study indicated regulated expression of approximately 5000 genes in the perilesional cortex and 


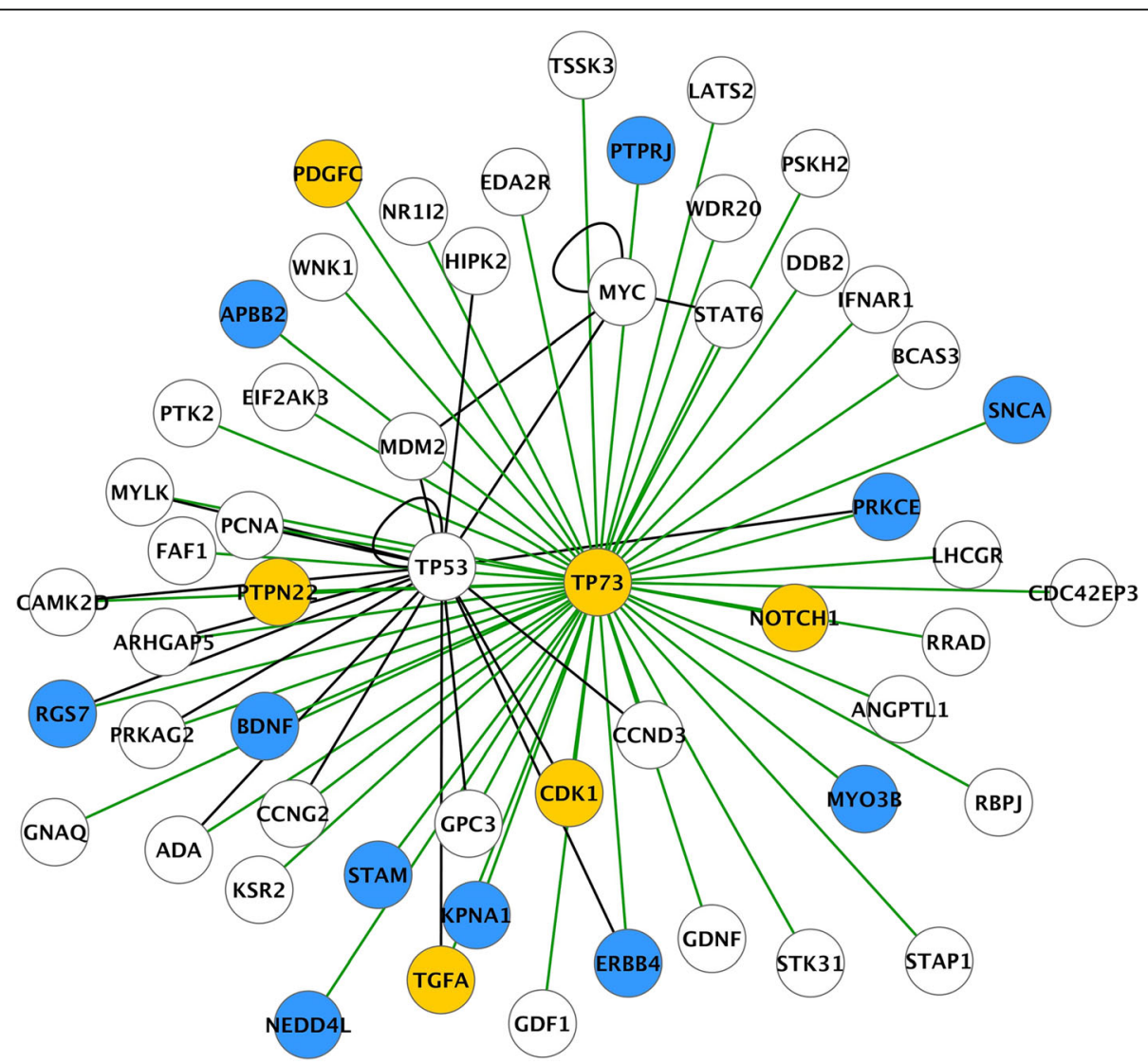

Fig. 3 SignaLink transcription regulatory network (TRN) of Tp73 and its targets in the perilesional cortex. SignaLink network analysis revealed 54 targets, of which five were upregulated and 11 were downregulated in the perilesional cortex 3 months post-TBI. Color codes: blue circle, downregulation after TBl; yellow circle, upregulation after TBl; white circle, no change in gene expression after TBl; green line, transcriptional interaction with Tp73; black line, inter-target interaction

1900 in the thalamus at 3 months after lateral FPIinduced TBI. in particular, we found a positive enrichment of inflammation-related genes and downregulation of ion channel-related genes [69]. The mechanisms that regulate chronic gene expression, however, remained unclear. Our transcriptomic data suggest that gene expression alterations could not be explained only by changes in the local cell populations [69]. One potential major regulator could be DNA-methylation, which regulates gene expression in several brain diseases, including Alzheimer's' disease [19], Parkinson's disease [51], amyotrophic lateral sclerosis [32], epilepsy [127], and TBI [39, $83,102,106]$. To explore the significance of DNA methylation as a regulator of chronically detected transcriptomics changes, we carried out genome-wide MBD-seq and RNA-seq from the perilesional cortex, ipsilateral thalamus, and ipsilateral hippocampus at 3 months post-TBI.

Regulated methylation was associated with altered gene expression only in the perilesional cortex. GSEA analysis revealed that the most enriched DNA methylation patterns in the perilesional cortex after TBI were in the gene promoter area. Specifically, MBD-seq indicated altered methylation in promoters of the Lrp1b, Gpr12, Wrd26, and Ppid genes. Pyrosequencing, however, did not confirm the sequencing data. This could relate to a low, although consistent, read count per methylation site in the promoter region $(<200)$ in the MBD-seq. Our negative findings are in agreement with previous studies in fluid-percussion injury, controlled cortical injury, weight-drop, and blast-induced TBI models, which reported no changes in the promoter methylation of Lrp1b, Gpr12, Wrd26 and Ppid genes in cortical, hippocampal, or amygdaloid tissue sampled 3 days to 8 months post-injury $[39,83,102,106]$. We were not able to reproduce the altered methylation in the rat cortex at 8 months after blast TBI [39], in the rat amygdala at $48 \mathrm{~h}$ to $30 \mathrm{~d}$ after weight-drop-induced TBI [102], in the rat hippocampus at 3 and $14 \mathrm{~d}$ after controlled cortical impact [106], in the rat hippocampus at $7 \mathrm{~d}$ after fluid-percussion injury [83], or in the rat hippocampus 3 months after lateral fluid-percussion injury [20]. This is likely related to the different injury types and postinjury delays between the present and previous experimental studies. 
Table 3 SignaLink 2.0 transcription regulatory network (TRN) analysis of differentially expressed transcription factors and their up-regulated and down-regulated target genes in the perilesional cortex and the ipsilateral thalamus at 3 months after traumatic brain injury. The same targets that were up-regulated both in the perilesional cortex and ipsilateral thalamus or down-regulated both in the perilesional cortex and ipsilateral thalamus are bold fonts

\begin{tabular}{|c|c|c|c|c|c|c|c|c|c|c|}
\hline \multirow[b]{2}{*}{ TF } & \multicolumn{5}{|c|}{ Perilesional cortex } & \multicolumn{5}{|c|}{ Ipsilateral thalamus } \\
\hline & $\mathrm{Log} 2 \mathrm{FC}$ & FDR & $\begin{array}{l}\text { Altered } \\
\text { targets/ } \\
\text { all } \\
\text { targets }\end{array}$ & $\begin{array}{l}\text { Upregulated } \\
\text { TF targets }\end{array}$ & $\begin{array}{l}\text { Downregulated } \\
\text { TF targets }\end{array}$ & Log2FC & FDR & $\begin{array}{l}\text { Altered } \\
\text { targets/ } \\
\text { all } \\
\text { targets }\end{array}$ & $\begin{array}{l}\text { Upregulated } \\
\text { TF targets }\end{array}$ & $\begin{array}{l}\text { Downregulated } \\
\text { TF targets }\end{array}$ \\
\hline Cebpd & 1.835 & $3.78 \mathrm{E}-034$ & $1 / 1$ & IGF1 & - & 1.261 & 7.47E-005 & $1 / 1$ & IGF1 & - \\
\hline Etv4 & -1.105 & 2.03E-008 & $0 / 1$ & - & - & -0.697 & 0.00523964 & $0 / 1$ & - & - \\
\hline Myb & 1.350 & 0.0042262 & $0 / 3$ & - & - & ns & ns & - & - & - \\
\hline Pax6 & 1.186 & 5.97E-022 & $91 / 300$ & $\begin{array}{l}\text { ABCA1, ABL1, } \\
\text { BMP6, BTK, CAV2, } \\
\text { CDKL1, DAB2, } \\
\text { DAPP1, ERBB2IP, } \\
\text { FGFR1, FGR, } \\
\text { FOXO1, FYB, GAB1, } \\
\text { IL21R, ITGA8, } \\
\text { ITGB1, MAP3K1, } \\
\text { MET, MICAL1, } \\
\text { MTSS1, NEDD1, } \\
\text { NIM1, PRKD1, } \\
\text { PTPRZ1, ROR2, } \\
\text { SKAP2, STK10, SYK, } \\
\text { TGFA, TICAM2, } \\
\text { UBE2U }\end{array}$ & $\begin{array}{l}\text { AKT3, ARHGAP32, } \\
\text { ATF2, BIRC6, BMPR2, } \\
\text { CAMK1D, CHN1, } \\
\text { CHRNA7, CNKSR2, } \\
\text { CTNND2,DAB, } \\
\text { DMXL2, EFNA5, } \\
\text { EPHA7, EPHB2, } \\
\text { ERBB4, ESRRG, } \\
\text { GABRB3, } \\
\text { GRB2,GRIA1, GRIA4, } \\
\text { GRIK3, GRIN2A, } \\
\text { ITPR1, MAGI2, } \\
\text { MAP3K13, MAPK10, } \\
\text { MAPK8IP3, MEF2C, } \\
\text { MRAS, NEDD4L, } \\
\text { NLK, NRD1, NRG1, } \\
\text { NRG3, NUAK1, PAK7, } \\
\text { PAM, PCSK5, PDE4D, } \\
\text { PLCB1, PRKCA, } \\
\text { PRKCB, PTPRG, } \\
\text { PTPRJ, PTPRK, PTPRT, } \\
\text { RAB14, RAP1GDS1, } \\
\text { RGS7, ROCK2, } \\
\text { RPS6KC1, RPTOR, } \\
\text { SH3GL2, SNRK, } \\
\text { SORBS2, TRIM33, } \\
\text { TTBK2, ZFYVE9 }\end{array}$ & 0.779 & $8.41 \mathrm{E}-5$ & $33 / 300$ & $\begin{array}{l}\text { ABCA1, ATF1, } \\
\text { BTK, DAPP1, } \\
\text { EPHB1, } \\
\text { ERBB2IP, } \\
\text { ERBB4, FGF2, } \\
\text { FGR, GAB1, } \\
\text { GRB14, IL21R, } \\
\text { INPP5D, } \\
\text { ITGAM } \\
\text { ITGB1, PKP4, } \\
\text { PRKCA, TCF4, } \\
\text { TGFA }\end{array}$ & $\begin{array}{l}\text { ARHGAP32, } \\
\text { CAMK1D, } \\
\text { CHN1, DAPK1, } \\
\text { GRM1, MAP3K14, } \\
\text { MAPK10, } \\
\text { NEDD4L, NRG2, } \\
\text { PRKCB, } \\
\text { RAP1GDS1, SRC, } \\
\text { STRADB, TRIO }\end{array}$ \\
\hline Spi1 & 1.021 & $2.88 \mathrm{E}-011$ & $1 / 3$ & LSP1 & - & 1.310 & 8.57E-006 & $1 / 3$ & LSP1 & - \\
\hline Tp73 & 1.328 & 0.01004339 & $15 / 54$ & $\begin{array}{l}\text { TGFA, PTPN22, } \\
\text { CDK1, PDGFC, } \\
\text { NOTCH1 }\end{array}$ & $\begin{array}{l}\text { BDNF, RGS7, ERBB4, } \\
\text { SNCA, PRKCE, PTPRJ, } \\
\text { NEDD4L, KPNA1, } \\
\text { APBB2, STAM, } \\
\text { MYO3B }\end{array}$ & ns & ns & $6 / 55$ & $\begin{array}{l}\text { MYLK } \\
\text { NEDD4L }\end{array}$ & $\begin{array}{l}\text { RRAD, TGFA, } \\
\text { ERBB4, PCNA }\end{array}$ \\
\hline
\end{tabular}

Abbreviations: FDR false discovery rate, ns non-significant, TF transcription factor

TRN analysis revealed transcription factors Cebpd, Pax6, Spi1 and Tp73 as regulators of chronically altered post-TBI gene expression

To identify the master switch that regulates the massively altered gene expression at 3 months post-TBI, we next investigated the possible contribution of transcription factors by integrating transcriptomics data into the Signalink 2.0 database. Laboratory validation of top hits using ddPCR confirmed the predicted mRNA upregulation of four transcription factors, Pax6, Tp73, Cebpd, and Spi1, in the perilesional cortex.

Pax6 showed a 6.7-fold upregulation, and almost 30\% (91 or 300) of its target genes were regulated in the perilesional cortex. The function of Pax6 in the cerebral cortex is unknown. In the hippocampus, Pax6 controls the differentiation and migration of neuronal progenitor cells (NPC) [37], which show regenerative potential after ischemic injury [88]. Moreover, overexpression of Pax6 improved the cellular viability of SH-SY5Y cells exposed to neurotoxin [119]. These studies suggest that upregulation of Pax6 after TBI could play a reparative role.

Tp73 showed a 1.6-fold upregulation, and approximately $30 \%$ (15 of 54 ) of its target genes were regulated in the perilesional cortex after TBI. The Tp73 gene has two promoters, producing two protein isoforms with different functions [86]. The $\Delta N p 73$ isoform is anti-apoptotic during development of the mouse superior cervical ganglion neurons [95]. Furthermore, $\Delta \mathbf{N p} 73$ is vital for long-term 
Table 4 Gene expression validation of genes encoding transcription factors using $d d P C R$ in the rat perilesional cortex, thalamus and hippocampus at three months after TBI

\begin{tabular}{|c|c|c|c|c|}
\hline & Cebpd & Pax6 & Spil & Tp73 \\
\hline \multicolumn{5}{|l|}{ Perilesional cortex } \\
\hline Fold change & 2.58 & 1.64 & 1.75 & 6.67 \\
\hline p-value & 0.0003996 & 0.004795 & 0.007592 & 0.0007992 \\
\hline \multicolumn{5}{|l|}{ Thalamus } \\
\hline Fold change & 1.55 & 1.13 & 1.65 & 0.55 \\
\hline p-value & 0.2721 & 0.4559 & 0.06633 & 0.3884 \\
\hline \multicolumn{5}{|l|}{ Hippocampus } \\
\hline Fold change & 0.74 & 0.91 & 1.00 & 0.79 \\
\hline$p$-value & 0.1375 & 0.7308 & 0.6282 & 0.6282 \\
\hline
\end{tabular}

Statistical significances: Fold change and corresponding $p$-value $(<0.05)$ are shown in bolded font

survival of mouse superior cervical ganglion and cortical neurons [66, 94]. The TAp73 isoform, however, induces apoptosis in SAOS-2 and medulloblastoma cell cultures $[11,50]$. Further studies are needed to explore the functional consequences of Tp73 upregulation after TBI.

Cebpd, also known as NF-IL6 $\beta$, regulates immune and inflammatory responses [57, 101]. Cebpd showed a 2.6fold upregulation, and its predicted target gene, IGF-1, was also upregulated in the perilesional cortex at 3 months post-TBI. There are some reports of increased expression of Cebpd in the cortex already at $2 \mathrm{~h}$ to $7 \mathrm{~d}$ after injury in various experimental models of TBI, including a controlled cortical impact mouse model $[48,105,128]$ and a weight-drop rat model $[16,123]$. These studies propose a wide time window for the post-injury regulation of Cebpd and its target IGF-1. It remains a testable hypothesis that chronic upregulation of Cebpd and IGF-1 genes relates to the control of chronic inflammation after TBI, as recently suggested in favorable proof-of-concept preclinical studies in injury models $[75,96,110,120]$.

Spi1 showed a 1.8-fold upregulation at 3 months post-TBI. Spi1 is expressed in microglia [126], which become activated after TBI [13, 61, 124]. Spi1 encodes PU.1, which appears vital for microglial survival [111]. Our TRN network analysis revealed three gene targets for Spi1, and of those, Lsp1 was upregulated in the perilesional cortex and ipsilateral thalamus at 3 months post-TBI. Lsp1 was reported to be upregulated in the rat cerebral cortex at $24 \mathrm{~h}$ after controlled cortical impact-induced TBI [128]. Spi1 regulates monocyte and macrophage differentiation [100], and has a crucial role in the normal development of $\mathrm{T}$ cells, B cells, neutrophils, and macrophages [82], which are important players in the post-TBI systemic inflammatory response [110].

In summary, our findings indicate that four transcription factors, Pax6, Tp73, Cepbd, and Spi1, serve as major chronic post-TBI transcriptomics regulators, and are thus potential targets for treatments.

Table 5 LINCS database analysis identified compounds that up-regulate or down-regulate the gene expression of Cebpd, Pax6, Spi1 and Tp73 transcription factors. Identification of compounds regulating the expression of transcription factors were carried out by retrieving compound-induced transcription profiles in terminally differentiated neurons, terminally differentiated neurons treated with $\mathrm{KCl}$, and iPS-derived neural progenitor cells

\begin{tabular}{|c|c|c|}
\hline TF & Upregulating compounds & Downregulating compounds \\
\hline Cebpd & $\begin{array}{l}\text { aminobenztropine (NEU), BG-1002 (NEU.KCL), BG-1011 (NPC), BIIB021 (NPC), BRD-A06779035 } \\
\text { (NPC), BRD-A70591769 (NEU), BRD-A75769921 (NEU.KCL), BRD-A92334183 (NEU), BRD-K01608965 } \\
\text { (NPC), BRD-K07381195 (NPC), BRD-K12683703 (NPC), BRD-K15050703 (NPC), BRD-K159356955 } \\
\text { (NPC), BRD-K16934333 (NPC), BRD-K20126873 (NPC), BRD-K21374126 (NPC), BRD-K23986500 } \\
\text { (NPC), BRD-K24798550 (NPC), BRD-K25164076 (NPC), BRD-K25990552 (NEU), BRD-K28934562 } \\
\text { (NPC), BRD-K30229575 (NPC), BRD-K32885145 (NPC), BRD-K36269259 (NEU), BRD-K36313546 } \\
\text { (NPC), BRD-K36591038 (NPC), BRD-K36796217 (NPC), BRD-K39597586 (NPC), BRD-K40300908 } \\
\text { (NPC), BRD-K41871066 (NPC), BRD-K43631199 (NPC), BRD-K44540157 (NPC), BRD-K49111930 } \\
\text { (NPC), BRD-K54331210 (NPC), BRD-K55536701 (NPC), BRD-K57166447 (NPC), BRD-K58808184 } \\
\text { (NPC), BRD-K59253994 (NPC), BRD-K62970326 (NPC), BRD-K63494246 (NEU), BRD-K64523453 } \\
\text { (NPC), BRD-K65148580 (NPC), BRD-K65657366 (NPC), BRD-K72354054 (NPC), BRD-K73008154 } \\
\text { (NPC), BRD-K77888550 (NPC), BRD-K78133682 (NPC), BRD-K79947405 (NPC), BRD-K80062189 } \\
\text { (NPC), BRD-K80138901 (NPC), BRD-K80400482 (NEU), BRD-K85133207 (NPC), BRD-K86110682 } \\
\text { (NPC), BRD-K91844626 (NEU), BRD-K93158953 (NPC), BRD-K99718824 (NPC), cabergoline (NEU), } \\
\text { chlorpromazine (NEU), deoxycholic-acid (NEU), econazole (NPC), farnesylthioacetic-acid (NPC), } \\
\text { fluspirilene (NEU), geldanamycin (NPC), GSK-461364 (NPC), GW-3965 (NPC), GW-441756 (NPC), } \\
\text { IQ1 (NEU), IQ1 (NPC), isoflupredone (NPC), ITSA-1 (NPC), IVP-2 (NEU), LY-255283 (NPC), LY- } \\
\text { 294002 (NPC), menadione (NPC), NVP-BEZ235 (NPC), PD-173074 (NPC), Pl-828 (NPC), quercetin } \\
\text { (NPC), R-96544 (NPC), scoulerine (NPC), serotonin (NPC), spermidine (NEU), SR-142948 (NEU), ST- } \\
\text { 023431 (NPC), ST-056792 (NPC), suberoyl-bis-hydroxamic-acid (NEU), tamoxifen (NPC), tozasertib } \\
\text { (NPC), tranylcypromine (NEU.KCL), triacetylresveratrol (NPC), trichostatin-a (NEU), trifluridine } \\
\text { (NPC), vorinostat (NPC) }\end{array}$ & BRD-K89824424 (NPC), O-1918 (NPC) \\
\hline Pax6 & $\begin{array}{l}\text { acetyl-farnesyl-cysteine (NEU.KCL), BRD-K02409808 (NEU), BRD-K24656059 (NPC), BRD-K45842176 } \\
\text { (NPC), clofibric-acid (NPC), rolipram (NPC), SKF-96365 (NPC), thioproperazine (NPC) }\end{array}$ & $\begin{array}{l}\text { apicidin (NEU.KCL), BG-1016 (NPC), BRD-K37650321 (NEU), } \\
\text { chrysamine-g (NEU), proadifen (NPC), XMD-1150 (NEU) }\end{array}$ \\
\hline Spil & BRD-K39172790 (NEU), timosaponin (NEU) & AS-703026 (NPC), genistein (NPC), U-0126 (NPC) \\
\hline$T p 73$ & $\begin{array}{l}\text { BRD-K16827616 (NPC), BRD-K78133682 (NPC), RG-14620 (NPC), trimipramine (NEU), wortmannin } \\
\text { (NEU) }\end{array}$ & - \\
\hline
\end{tabular}


LINCS analysis revealed transcription factor-targeting antidepressants and anti-cancer drugs as novel treatment candidates for TBI

Next, we performed a LINCS analysis to identify compounds that modulate the gene expression of Pax6, Tp73, Cepbd, or Spi1. The largest number of compounds identified targeted Cebpd. Most of the compounds upregulating Cebpd were bioactive (starting with BRD) without any known therapeutic actions. The analysis, however, also identified antidepressants and anti-cancer drugs that are already used in the clinic. Tranylcypromine, an antidepressant and monoamine oxidase inhibitor (MAO-I) [29], is a promising therapy as MAO-Is have neuroprotective effects in mice with TBI [44]. Tranylcypromine also alleviates neurodegeneration and inflammation by inhibiting prostacyclin and arachidonic acid release in calf primary endothelial cells [34, 43]. LINCS analysis also revealed fluspirilene and chlorpromazine as upregulators of Cepbd. Duotherapy with chlorpromazine and promethazine was demonstrated to be neuroprotective when assessed at $24 \mathrm{~h}$ after brain ischemia in rats [35]. Chlorpromazine suppressed neuronal apoptosis in the rat parietal cortex and the CA1 subfield of the hippocampus when assessed at $24 \mathrm{~h}$ after ethanol-induced apoptosis [131]. Chlorpromazine also reduced the cerebral infarct size when assessed at $24 \mathrm{~h}$ post-ischemia in rats [68].

In addition to compounds used in psychiatry, LINCS analysis revealed an anti-cancer drug, vorinostat, a histone deacetylase inhibitor (HDAC1-3 and 6) [77] as an upregulator of Cepbd. Vorinostat attenuated neurodegeneration and improved neurological outcome when assessed at $24 \mathrm{~h}$ after stroke in rats [117]. Interestingly, valproate, another HDAC inhibitor (HDAC1-3 and 8) [6], is neuroprotective and anti-inflammatory in rodent models of TBI and ischemia [18, 55, 132]. Tamoxifen was another upregulator of Cepbd identified by the LINCS analysis. Tamoxifen is a selective estrogen receptor modulator [107] used to treat breast cancer [33]. Tamoxifen reduced the cerebral infarct volume and neuronal apoptosis when assessed at $72 \mathrm{~h}$ after fluid-percussion injury in rats [121]. LINCS analysis also revealed two compounds that downregulated Cebpd, O-1918 and BRD-K89824424. Information available from O-1918 indicates that it is a cannabidiol analog, acting as a selective antagonist of abnormal cannabidiol at the non- $\mathrm{CB}_{1} / \mathrm{CB}_{2}$ endothelial receptor [89, 135]. Interestingly, another cannabinoid receptor antagonist, AM630, counteracted the recovery-enhancing effects of leptin [71]. Moreover, SR144528, a cannabinoid receptor antagonist increased TNF $\alpha$ gene expression $24 \mathrm{~h}$ after mouse controlled cortical impact $(\mathrm{CCI})$, suggesting that it enhances the inflammatory response [2]. Taken together, these studies suggest that upregulation of Cebpd favorably modifies the post-TBI outcome.
LINCS analysis revealed SKF-96365, thioproperazine, and rolipram as upregulators of Pax6. SKF-96365 is an inhibitor of receptor-mediated calcium entry [84]. In an in vitro model of bovine brain microvessel endothelial cells, SKF-96365 decreased blood-brain barrier permeability [1], a major pathology in TBI. Thioproperazin is a neuroleptic that increases dopamine release [12]. Interestingly, dopamine release was decreased at 1 week after TBI in the rat CCI model [109], and an increase in dopamine level by methylphenidate improved spatial memory based on a shorter Morris water-maze latency at $14 \mathrm{~d}$ after rat CCI [58]. Rolipram, an antidepressant, MAO-I, and phosphodiesterase (PDE) IV inhibitor, also upregulates Pax6 gene expression. It suppresses cytokine production in human and rat $\mathrm{T}$ cells [114]. Moreover, rolipram inhibits neuronal damage in gerbil CA1 hippocampus $7 \mathrm{~d}$ after stroke [53]. Rolipram also reduced infarct size, improved neurological outcome, increased anti-inflammatory cytokines, and decreased pro-inflammatory cytokines at $24 \mathrm{~h}$ after mouse focal cerebral ischemia [62]. LINCS analysis revealed that Pax6 was downregulated by proadifen, a cytochrome P-450 inhibitor [10], and by apicidin, a histone deacetylase inhibitor [41]. Interestingly, apicidin induced apoptosis in MCF-7 cells through cell cycle regulatory proteins [45] and reversed nitric oxide and inducible nitric oxide synthase expression induced by dexamethasone and RU24858 in a mouse macrophage cell culture [40]. Taken together, upregulation of Pax6 gene expression appears to be a target for favorable modulation of the post-TBI outcome by reversing the reduced dopamine release and reducing neuroinflammation via cytokine release, as suggested by studies of thioproperazine and rolipram. Moreover, both Cepbd and Pax6 are upregulated by compounds with an MAO-I mechanism, and are predicted to have favorable effects.

LINCS analysis revealed two compounds that upregulate Spi1. From these, timosaponin AIII is a candidate anti-cancer drug [52, 118]. It reverses scopolamineinduced memory impairment in mice [67]. LINCS analysis revealed three compounds that downregulated Spi1. AS-703026 (also known as pimasertib) and U0126 are MEK $1 / 2$ inhibitors $[30,56]$. U0126 has favorable effects on recovery in various in vivo brain injury models. For example, it reduced infarct size when assessed at $24 \mathrm{~h}$ after middle cerebral artery occlusion in rats [27], lesion size when analyzed at $7 \mathrm{~d}$ after in mice injured with controlled cortical impact [87], and microglial activation in the ischemia model of spinal cord injury in rats [73]. Genistein, a phytoestrogen with a broad spectrum of pharmacological properties, inhibits protein tyrosine kinases and topoisomerase II, and exhibits estrogen-like activity [23, 93]. Genistein showed neuroprotective effects when assessed at $48 \mathrm{~h}$ after 
weight-drop-induced TBI [113] and at $24 \mathrm{~h}$ after focal cerebral ischemia in rats [4]. Whether downregulators of Spi1 will have favorable effects on more chronic postTBI outcome remains to be investigated.

LINCS analysis revealed three compounds with some prior information of biological effects, all of which upregulated Tp73. Wortmannin, a radiosensitizer, is a phosphoinositide 3-kinase inhibitor [5] that also inhibits MTOR in vitro, a pathway involved in post-TBI recovery and epileptogenesis in several post-injury animal models $[8,92]$. Trimipramine is a tricyclic antidepressant [103] that reduced interferon- $\gamma$ production, suppressed T-cell proliferation, and increased interleukin-12 production in concanavalin Astimulated human whole blood cultures [21]. The effects of trimipramine on brain injury, however, are poorly described. RG-14620 is a protein tyrosine kinase inhibitor with antiproliferative effects [134]. Compounds that upregulate Tp73 expression are interesting candidates for further studies. For example, trimipramine is already used in the clinic and could be repurposed to improve outcome after TBI.

\section{Conclusions}

This is the first analysis of chronic regulation of gene expression after TBI, demonstrating that chronic post-TBI transcriptional regulation is more under the control of transcription factors than DNA methylation. In particular, four upregulated transcription factors Pax6, Tp 73, Cebpd, and Spi1, appeared as potent regulators of chronic post-TBI gene expression. They regulate the molecular networks contributing to post-injury secondary damage, including apoptosis and inflammation, strengthening the feasibility of therapeutically targeting these molecular networks even after the acute post-TBI period. To complement hypothesis-driven therapeutic approaches, our systemsbiology driven unbiased LINCS database analysis revealed several novel treatment candidates. In particular, our data together with a literature search of effects in in vitro and in vivo models of brain injury revealed that antidepressant/ neuroleptics such as trimipramine, rolipram, fluspirilene, and chlorpromazine, as well as the anti-cancer therapies pimasertib, tamoxifen, and vorinostat are candidates for further testing to favorably modulate regulated transcriptomics networks and post-TBI outcome.

\section{Additional files}

\section{Additional file 1: Pyrosequencing assays. (DOCX $16 \mathrm{~kb}$ )}

Additional file 2: Gene expression of astrocyte, microglia and neuronal markers in the perilesional cortex and ipsilateral thalamus in RNA-seq dataset. (DOCX $16 \mathrm{~kb}$ )

Additional file 3: Dot plots and correlations of the read counts of transcription factors with the read counts of neuronal, microglial and astroglial markers. (DOCX 55 kb)

\section{Abbreviations}

CCI: Controlled cortical impact; ddPCR: Digital droplet polymerase chain reaction; FDR: False discovery rate; FPI: Fluid-percussion injury; GSEA: Gene Set Enrichment Analysis; HDAC: Histone deacetylase inhibitor; MAO-I: Monoamine oxidase inhibitor; MBD-seq: Methyl-binding domain sequencing; NEU: Terminally differentiated neurons; NEU.KCL: Terminally differentiated neurons treated with KCl; NPC: iPS-derived neural progenitor cells; RIN: RNA integrity number; RNA-seq: RNA-sequencing; STAR: Spliced Transcripts Alignment to a Reference; TBI: Traumatic brain injury; TRN: Transcription regulatory network

\section{Acknowledgements}

We thank Mr. Jarmo Hartikainen and Mrs. Merja Lukkari for their excellent technical assistance. We are also grateful to Mr. Juha Kekäläinen and Oskari Timonen (MSc) for their excellent help with the bioinformatics analysis.

\section{Funding}

This study was supported by the Academy of Finland (A.P.), EpiGENet EUROEPINOMICS (A.P.), and FP7-HEALTH project 602102 (EPITARGET)(AP).

\section{Availability of data and materials}

The RNA and MBD-seq datasets generated and analysed during the current study are available in the NCBI's Gene Expression Omnibus [26]. RNA-seq GEO series accession number GSE80174 (http://www.ncbi.nlm.nih.gov/geo/ query/acc.cgi?acc=GSE80174) and MBD-seq GSE107837 (https://

www.ncbi.n/m.nih.gov/geo/query/acc.cgi?acc=GSE107837).

\section{Authors' contributions}

AL and AP wrote the main manuscript text. NP sampled rat brain. AEO, AK, $\mathrm{MZ}$ and $\mathrm{HKH}$ did NGS sequencing. AL and JP conducted bioinformatics analyses. VN-F and AL made validations. All authors read and approved the final manuscript.

\section{Ethics approval}

All animal operations were approved by The Animal Ethics Committee of the Provincial Government of Southern Finland and carried out according to the guidelines of the European Community Council Directives 2010/63/EU.

\section{Consent for publication}

Not applicable.

\section{Competing interests}

The authors declare that they have no competing interests.

\section{Publisher's Note}

Springer Nature remains neutral with regard to jurisdictional claims in published maps and institutional affiliations.

\section{Author details}

${ }^{1}$ Epilepsy Research Laboratory, A. I. Virtanen Institute for Molecular Sciences, University of Eastern Finland, PO Box 1627, FIN-70211 Kuopio, Finland.

${ }^{2}$ Epigenetics in Human Health and Disease Laboratory, Central Clinical School, Faculty of Medicine, Monash University, Melbourne, VIC, Australia. ${ }^{3}$ Prince of Wales Hospital, The Chinese University of Hong Kong, Sha Tin, Hong Kong SAR. ${ }^{4}$ Institute of Biomedicine, University of Eastern Finland, Kuopio, Finland. ${ }^{5}$ University of Eastern Finland Bioinformatics Center, University of Eastern Finland, Kuopio, Finland.

Received: 8 January 2018 Accepted: 15 February 2018

Published online: 27 February 2018

References

1. Abbruscato TJ, Davis TP (1999) Combination of hypoxia/Aglycemia compromises in vitro blood-brain barrier integrity. J Pharmacol Exp Ther 289:668-678

2. Amenta PS, Jallo Jl, Tuma RF, Hooper DC, Elliott MB (2014) Cannabinoid receptor type-2 stimulation, blockade, and deletion alter the vascular inflammatory responses to traumatic brain injury. J Neuroinflammation 11:191

3. Andrews S. FastQC: A quality control tool for high throughput sequence data. 2010. https://www.bioinformatics.babraham.ac.uk/projects/fastac/. Accessed 25 Nov 2017 
4. Aras AB, Guven M, Akman T, Alacam H, Kalkan Y, Silan C et al (2015) Genistein exerts neuroprotective effect on focal cerebral ischemia injury in rats. Inflammation 38:1311-1321

5. Arcaro A, Wymann MP (1993) Wortmannin is a potent phosphatidylinosito 3-kinase inhibitor: the role of phosphatidylinositol 3,4,5-trisphosphate in neutrophil responses. Biochem J 296:279-301.

6. Atmaca A, Al-Batran S-E, Maurer A, Neumann A, Heinzel T, Hentsch B et al (2007) Valproic acid (VPA) in patients with refractory advanced cancer: a dose escalating phase I clinical trial. Br J Cancer 97:177-182

7. Bramlett HM, Dietrich WD, Green EJ, Busto R (1997) Chronic histopathological consequences of fluid-percussion brain injury in rats: effects of post-traumatic hypothermia. Acta Neuropathol 93:190-199

8. Brunn GJ, Williams J, Sabers C, Wiederrecht G, Lawrence JC, Abraham RT et al (1996) Direct inhibition of the signaling functions of the mammalian target of rapamycin by the phosphoinositide 3-kinase inhibitors, wortmannin and LY294002. EMBO J 15:5256-5267

9. Buffo A, Vosko MR, Ertürk D, Hamann GF, Jucker M, Rowitch D et al (2005) Expression pattern of the transcription factor Olig2 in response to brain injuries: implications for neuronal repair. Proc Natl Acad Sci U S A 102: 18183-18188

10. Capdevila J, Gil L, Orellana M, Marnett LJ, Mason JI, Yadagiri P et al (1988) Inhibitors of cytochrome P-450-dependent arachidonic acid metabolism. Arch Biochem Biophys 261:257-263

11. Castellino RC, De Bortoli M, Lin LL, Skapura DG, Rajan JA, Adesina AM et a (2007) Overexpressed TP73 induces apoptosis in medulloblastoma. BMC Cancer 7:127

12. Cheramy A, Besson MJ, Glowinski J (1970) Increased release of dopamine from striatal dopaminergic terminals in the rat after treatment with a neuroleptic: Thioproperazine. Eur J Pharmacol 10:206-214

13. Chiu C-C, Liao Y-E, Yang L-Y, Wang J-Y, Tweedie D, Karnati HK et al (2016) Neuroinflammation in animal models of traumatic brain injury. J Neurosci Methods 272:38-49

14. Colak T, Cine N, Bamac B, Kurtas O, Ozbek A, Bicer U et al (2012) Microarraybased gene expression analysis of an animal model for closed head injury. Injury 43:1264-1270

15. Corrigan JD, Selassie AW, Orman JAL (2010) The epidemiology of traumatic brain injury. J Head Trauma Rehabil 25:72-80

16. Crack PJ, Gould J, Bye N, Ross S, Ali U, Habgood MD et al (2009) The genomic profile of the cerebral cortex after closed head injury in mice: effects of minocycline. J Neural Transm 116:1-12

17. Crawford F, Wood M, Ferguson S, Mathura V, Gupta P, Humphrey J et al (2009) Apolipoprotein E-genotype dependent hippocampal and cortical responses to traumatic brain injury. Neuroscience 159:1349-1362

18. Dash PK, Orsi SA, Zhang M, Grill RJ, Pati S, Zhao J et al (2010) Valproate administered after traumatic brain injury provides neuroprotection and improves cognitive function in rats. PLoS One 5:e11383

19. De Jager $P L$, Srivastava $G$, Lunnon K, Burgess J, Schalkwyk LC, Yu L et al (2014) Alzheimer's disease: early alterations in brain DNA methylation at ANK1, BIN1, RHBDF2 and other loci. Nat Neurosci 17:1156-1163

20. Dębski KJ, Pitkanen A, Puhakka N, Bot AM, Khurana I, Harikrishnan KN et al (2016) Etiology matters - genomic DNA methylation patterns in three rat models of acquired epilepsy. Sci Rep 6:25668

21. Diamond M, Kelly JP, Connor TJ (2006) Antidepressants suppress production of the Th1 cytokine interferon- $\gamma$, independent of monoamine transporter blockade. Eur Neuropsychopharmacol 16:481-490

22. Diaz-Arrastia R, Kochanek PM, Bergold P, Kenney K, Marx CE, Grimes CJB et al (2014) Pharmacotherapy of traumatic brain injury: state of the science and the road forward: report of the Department of Defense Neurotrauma Pharmacology Workgroup. J Neurotrauma 31:135-158

23. Dixon RA, Ferreira D (2002) Genistein. Phytochemistry 60:205-211

24. Dobin A, Davis CA, Schlesinger F, Drenkow J, Zaleski C, Jha S et al (2013) STAR: ultrafast universal RNA-seq aligner. Bioinformatics 29:15-21

25. Dougall D, Poole N, Agrawal N (2015) Pharmacotherapy for chronic cognitive impairment in traumatic brain injury. Cochrane Database Syst Rev 12:CD009221

26. Edgar R, Domrachev M, Lash AE (2002) Gene expression omnibus: NCBI gene expression and hybridization array data repository. Nucleic Acids Res 30:207-210

27. Farrokhnia N, Ericsson A, Terént A, Lennmyr F (2008) MEK-inhibitor U0126 in hyperglycaemic focal ischaemic brain injury in the rat. Eur J Clin Investig 38:679-685

28. Faul M, Xu L, Wald MM, Coronado VG. Traumatic Brain Injury in the United States: Emergency Department Visits, Hospitalizations and Deaths 20022006. Atlanta (GA): Centers for Disease Control and Prevention, National
Center for Injury Prevention and Control; 2010. https://www.cdc.gov/ traumaticbraininjury/pdf/blue_book.pdf

29. Fava M, Kendler KS (2000) Major depressive disorder. Neuron 28:335-341

30. Favata MF, Horiuchi KY, Manos EJ, Daulerio AJ, Stradley DA, Feeser WS et al (1998) Identification of a novel inhibitor of mitogen-activated protein kinase kinase. J Biol Chem 273:18623-18632

31. Fazekas D, Koltai M, Türei D, Módos D, Pálfy M, Dúl Z et al (2013) SignaLink 2 - a signaling pathway resource with multi-layered regulatory networks. BMC Syst Biol 7:7

32. Figueroa-Romero C, Hur J, Bender DE, Delaney CE, Cataldo MD, Smith AL et al (2012) Identification of epigenetically altered genes in sporadic amyotrophic lateral sclerosis. Idong, editor. PLoS One 7:e52672

33. Fisher B, Costantino JP, Wickerham DL, Redmond CK, Kavanah M, Cronin WM et al (1998) Tamoxifen for prevention of breast cancer: report of the National Surgical Adjuvant Breast and Bowel Project P-1 Study. J Natl Cancer Inst 90:1371-1388

34. Frieling H, Bleich S (2006) Tranylcypromine. Eur Arch Psychiatry Clin Neurosci 256:268-273

35. Geng X, Li F, Yip J, Peng C, Elmadhoun O, Shen J et al (2017) Neuroprotection by chlorpromazine and promethazine in severe transient and permanent ischemic stroke. Mol Neurobiol 54:8140

36. Gentleman SM, Leclercq PD, Moyes L, Graham DI, Smith C, Griffin WST et al (2004) Long-term intracerebral inflammatory response after traumatic brain injury. Forensic Sci Int 146:97-104

37. Glaser T, Jepeal L, Edwards JG, Young SR, Favor J, Maas RL (1994) PAX6 gene dosage effect in a family with congenital cataracts, aniridia, anophthalmia and central nervous system defects. Nat Genet 7:463-471

38. Goodman JC, Cherian L, Robertson CS (2008) Cortical expression of prolactin (PRL), growth hormone $(\mathrm{GH})$ and adrenocorticotrophic hormone (ACTH) is not increased in experimental traumatic brain injury. Acta Neurochir Suppl 102:389-390

39. Haghighi F, Ge Y, Chen S, Xin Y, Umali MU, De Gasperi R et al (2015) Neuronal DNA methylation profiling of blast-related traumatic brain injury. J Neurotrauma 32:1200-1209

40. Hämäläinen M, Lilja R, Kankaanranta H, Moilanen E (2008) Inhibition of iNOS expression and NO production by anti-inflammatory steroids. Pulm Pharmacol Ther 21:331-339

41. Han JW, Ahn SH, Park SH, Wang SY, Bae GU, Seo DW et al (2000) Apicidin, a histone deacetylase inhibitor, inhibits proliferation of tumor cells via induction of p21WAF1/Cip1 and gelsolin. Cancer Res 60:6068-6074

42. Hellmich HL, Rojo DR, Micci M-A, Sell SL, Boone DR, Crookshanks JM et al (2013) Pathway analysis reveals common pro-survival mechanisms of metyrapone and carbenoxolone after traumatic brain injury. PLoS One 8:e53230

43. Hong SL, Carty T, Deykin D (1980) Tranylcypromine and 15hydroperoxyarachidonate affect arachidonic acid release in addition to inhibition of prostacyclin synthesis in calf aortic endothelial cells. J Biol Chem 255:9538-9540

44. Huang W, Chen Y, Shohami E, Weinstock M (1999) Neuroprotective effect of rasagiline, a selective monoamine oxidase-B inhibitor, against closed head injury in the mouse. Eur J Pharmacol 366:127-135

45. Im JY, Park H, Kang KW, Choi WS, Kim HS (2008) Modulation of cell cycles and apoptosis by apicidin in estrogen receptor (ER)-positive and-negative human breast cancer cells. Chem Biol Interact 172:235-244

46. Immonen RJ, Kharatishvili I, Niskanen JP, Gröhn H, Pitkänen A, Gröhn OHJ (2009) Distinct MRI pattern in lesional and perilesional area after traumatic brain injury in rat - 11 months follow-up. Exp Neurol 215:29-40

47. Ishikawa Y, Uchino H, Morota S, Li C, Takahashi T, Ikeda Y et al (2006) Search for novel gene markers of traumatic brain injury by time differential microarray analysis. Acta Neurochir Suppl 96:163-167

48. Israelsson C, Bengtsson $H$, Kylberg A, Kullander K, Lewén A, Hillered L et al (2008) Distinct cellular patterns of upregulated chemokine expression supportingok a prominent inflammatory role in traumatic brain injury. J Neurotrauma 25:959-974

49. Johnson V.E., Stewart W., Arena J.D., Smith D.H. (2017) Traumatic Brain Injury as a Trigger of Neurodegeneration. In: Beart P., Robinson M., Rattray M., Maragakis N, editors. Neurodegenerative Diseases. Advances in Neurobiology, vol 15. Springer, Cham. https://link.springer.com/chapter/10. 1007/978-3-319-57193-5_15\#citeas

50. Jost CA, Marin MC, Kaelin WG (1997) p73 is a human p53-related protein that can induce apoptosis. Nature 389:191-194 
51. Jowaed A, Schmitt I, Kaut O, Wullner U (2010) Methylation regulates alphaSynuclein expression and is decreased in Parkinson's disease patients' brains. J Neurosci 30:6355-6359

52. Kang Y-J, Chung H-J, Nam J-W, Park HJ, Seo EK, Kim YS et al (2011) Cytotoxic and antineoplastic activity of timosaponin A-III for human colon cancer cells. J Nat Prod 74:701-706

53. Kato H, Araki T, Itoyama Y, Kogure K (1995) Rolipram, a cyclic AMP-selective phosphodiesterase inhibitor, reduces neuronal damage following cerebral ischemia in the gerbil. Eur J Pharmacol 272:107-110

54. Kharatishvili I, Nissinen JP, Intosh TKMC, McIntosh TK, Pitkänen A (2006) A model of posttraumatic epilepsy induced by lateral fluid-percussion brain injury in rats. Neuroscience 140:685-697

55. Kim HJ, Rowe M, Ren M, Hong J-S, Chen P-S, Chuang D-M (2007) Histone deacetylase inhibitors exhibit anti-inflammatory and neuroprotective effects in a rat permanent ischemic model of stroke: multiple mechanisms of action. J Pharmacol Exp Ther 321:892-901

56. Kim K, Kong S-Y, Fulciniti M, Li X, Song W, Nahar S et al (2010) Blockade of the MEK/ERK signalling cascade by AS703026, a novel selective MEK1/2 inhibitor, induces pleiotropic anti-myeloma activity in vitro and in vivo. Br J Haematol 149:537-549

57. Kinoshita S, Akira S, Kishimoto T (1992) A member of the C/EBP family, NFIL6 beta, forms a heterodimer and transcriptionally synergizes with NF-IL6. Proc Natl Acad Sci U S A 89:1473-1476

58. Kline AE, Yan HQ, Bao J, Marion DW, Dixon CE (2000) Chronic methylphenidate treatment enhances water maze performance following traumatic brain injury in rats. Neurosci Lett 280:163-166

59. Kobori N, Clifton GL, Dash P (2002) Altered expression of novel genes in the cerebral cortex following experimental brain injury. Brain Res Mol Brain Res 104:148-158

60. Korcsmáros T, Farkas IJ, Szalay MS, Rovó P, Fazekas D, Spiró Z et al (2010) Uniformly curated signaling pathways reveal tissue-specific cross-talks and support drug target discovery. Bioinformatics 26:2042-2050

61. Koshinaga M, Katayama Y, Fukushima M, Oshima H, Suma T, Takahata T (2000) Rapid and widespread microglial activation induced by traumatic brain injury in rat brain slices. J Neurotrauma 17:185-192

62. Kraft P, Schwarz T, Göb E, Heydenreich N, Brede M, Meuth SG et al (2013) The phosphodiesterase-4 inhibitor rolipram protects from ischemic stroke in mice by reducing blood-brain-barrier damage, inflammation and thrombosis. Exp Neurol 247:80-90

63. Kukacka J, Vajtr D, Huska D, Prusa R, Houstava L, Samal F et al (2006) Blood metallothionein, neuron specific enolase, and protein S100B in patients with traumatic brain injury. Neuro Endocrinol Lett 27(Suppl 2):116-120

64. Laing AJ, Dillon JP, Condon ET, Street JT, Wang JH, McGuinness AJ et al (2007) Mobilization of endothelial precursor cells: systemic vascular response to musculoskeletal trauma. J Orthop Res 25:44-50

65. Langlois JA, Rutland-Brown W, Wald MM (2006) The epidemiology and impact of traumatic brain injury: a brief overview. J Head Trauma Rehabil 21:375-378

66. Lee AF, Ho DK, Zanassi P, Walsh GS, Kaplan DR, Miller FD (2004) Evidence that Np73 promotes neuronal survival by p53-dependent and p53independent mechanisms. J Neurosci 24:9174-9184

67. Lee B, Jung K, Kim D-H (2009) Timosaponin Alll, a saponin isolated from Anemarrhena asphodeloides, ameliorates learning and memory deficits in mice. Pharmacol Biochem Behav 93:121-127

68. Li H-J, Zhang Y-J, Zhou L, Han F, Wang M-Y, Xue M-Q et al (2014) Chlorpromazine confers neuroprotection against brain ischemia by activating BKCa channel. Eur J Pharmacol 735:38-43

69. Lipponen A, Paananen J, Puhakka N, Pitkänen A (2016) Analysis of posttraumatic brain injury gene expression signature reveals tubulins, Nfe2l2, Nfkb, Cd44, and S100a4 as treatment targets. Sci Rep 6:31570

70. Logan TT, Villapol S, Symes AJ, Kaltschmidt C, Kaltschmidt B (2013) TGF- $\beta$ superfamily gene expression and induction of the Runx 1 transcription factor in adult neurogenic regions after brain injury. Zheng JC, editor. PLoS One 8 : e59250

71. Lopez-Rodriguez AB, Mela V, Acaz-Fonseca E, Garcia-Segura LM, Viveros M-P (2016) CB2 cannabinoid receptor is involved in the anti-inflammatory effects of leptin in a model of traumatic brain injury. Exp Neurol 279:274-282

72. Love Ml, Huber W, Anders S (2014) Moderated estimation of fold change and dispersion for RNA-seq data with DESeq2. Genome Biol 15:550

73. Lu K, Cho C-L, Liang C-L, Chen S-D, Liliang P-C, Wang S-Y et al (2007) Inhibition of the MEK/ERK pathway reduces microglial activation and interleukin-1-beta expression in spinal cord ischemia/reperfusion injury in rats. J Thorac Cardiovasc Surg 133:934-941

74. Maas AIR, Menon DK, Steyerberg EW, Citerio G, Lecky F, Manley GT et al (2015) Collaborative European NeuroTrauma Effectiveness Research in Traumatic Brain injury (CENTER-TBI): a prospective longitudinal observational study. Neurosurgery 76:67-80

75. Madathil SK and Saatman KE. IGF-1/IGF-R Signaling in Traumatic Brain Injury In Kobeissy FH, editor. Brain Neurotrauma: Molecular, Neuropsychological, and Rehabilitation Aspects. Boca Raton (FL); CRC Press/Taylor \& Francis; 2015. https://www.ncbi.nlm.nih.gov/books/NBK299190/

76. Marklund N, Bakshi A, Castelbuono DJ, Conte V, McIntosh TK (2006) Evaluation of pharmacological treatment strategies in traumatic brain injury. Curr Pharm Des 12:1645-1680

77. Marks PA, Breslow R (2007) Dimethyl sulfoxide to vorinostat: development of this histone deacetylase inhibitor as an anticancer drug. Nat Biotechnol 25:84-90

78. Matzilevich DA, Rall JM, Moore AN, Grill RJ, Dash PK (2002) High-density microarray analysis of hippocampal gene expression following experimental brain injury. J Neurosci Res 67:646-663

79. McDonald SJ, Sun M, Agoston DV, Shultz SR (2016) The effect of concomitant peripheral injury on traumatic brain injury pathobiology and outcome. J Neuroinflammation 13:90

80. McGinn MJ and Povlishock JT. Cellular and molecular mechanisms of injury and spontaneous recovery. In: Grafman J and Salazar AM, editors. Handbook of Clinical Neurology. Elsevier; 2015. p. 67-87. https://doi.org/10.1016/B9780-444-52892-6.00005-2

81. McIntosh TK, Vink R, Noble L, Yamakami I, Fernyak S, Soares H et al (1989) Traumatic brain injury in the rat: characterization of a lateral fluid-percussion model. Neuroscience 28:233-244

82. McKercher SR, Torbett BE, Anderson KL, Henkel GW, Vestal DJ, Baribault H et al (1996) Targeted disruption of the PU.1 gene results in multiple hematopoietic abnormalities. EMBO J 15:5647-5658

83. Meng Q, Zhuang Y, Ying Z, Agrawal R, Yang X, Gomez-Pinilla F (2017) Traumatic brain injury induces genome-wide transcriptomic, Methylomic, and network perturbations in brain and blood predicting neurological disorders. EBioMedicine 16:184-194

84. Merritt JE, Armstrong WP, Benham CD, Hallam TJ, Jacob R, Jaxa-Chamiec A et al (1990) SK\&F 96365, a novel inhibitor of receptor-mediated calcium entry. Biochem J 271:515-522

85. Michael DB, Byers DM, Irwin LN (2005) Gene expression following traumatic brain injury in humans: analysis by microarray. J Clin Neurosci 12:284-290

86. Moll UM, Erster S, Zaika A (2001) p53, p63 and p73 - solos, alliances and feuds among family members. Biochim Biophys Acta - Rev Cancer 1552:47-59

87. Mori T, Wang X, Aoki T, Lo EH (2002) Downregulation of matrix Metalloproteinase-9 and attenuation of edema via inhibition of ERK mitogen activated protein kinase in traumatic brain injury. J Neurotrauma 19:1411-1419

88. Nakatomi H, Kuriu T, Okabe S, Yamamoto S, Hatano O, Kawahara N et al (2002) Regeneration of hippocampal pyramidal neurons after ischemic brain injury by recruitment of endogenous neural progenitors. Cell 110:429-441

89. Offertáler L, Mo F-M, Bátkai S, Liu J, Begg M, Razdan RK et al. (2003) Selective ligands and cellular effectors of a $\mathrm{G}$ protein-coupled endothelial cannabinoid receptor. Mol Pharmacol 63:699-705.

90. Peña-Llopis S, Brugarolas J (2013) Simultaneous isolation of high-quality DNA, RNA, miRNA and proteins from tissues for genomic applications. Nat Protoc 8:2240-2255

91. Pierce JE, Smith DH, Trojanowski JQ, McIntosh TK (1998) Enduring cognitive, neurobehavioral and histopathological changes persist for up to one year following severe experimental brain injury in rats. Neuroscience 87:359-369

92. Pitkänen A, Immonen R (2014) Epilepsy related to traumatic brain injury Neurotherapeutics 11:286-296

93. Polkowski K, Mazurek AP (2000) Biological properties of genistein. A review of in vitro and in vivo data. Acta Pol Pharm - Drug Res 57:135-155

94. Pozniak CD, Barnabé-Heider F, Rymar W, Lee AF, Sadikot AF, Miller FD (2002) p73 is required for survival and maintenance of CNS neurons. J Neurosci 22:9800-9809

95. Pozniak CD, Radinovic S, Yang A, McKeon F, Kaplan DR, Miller FD (2000) An anti-apoptotic role for the p53 family member, p73, during developmental neuron death. Science 289:304-306

96. Puche JE, Muñoz Ú, García-Magariño M, Sádaba MC, Castilla-Cortázar I (2016) Partial IGF-1 deficiency induces brain oxidative damage and edema, which are ameliorated by replacement therapy. Biofactors 42:60-79 
97. Rall JM, Matzilevich DA, Dash PK (2003) Comparative analysis of mRNA levels in the frontal cortex and the hippocampus in the basal state and in response to experimental brain injury. Neuropathol Appl Neurobiol 29:118-131

98. Ramlackhansingh AF, Brooks DJ, Greenwood RJ, Bose SK, Turkheimer FE, Kinnunen KM et al (2011) Inflammation after trauma: microglial activation and traumatic brain injury. Ann Neurol 70:374-383

99. Risling M, Plantman S, Angeria M, Rostami E, Bellander B-M, Kirkegaard M et al (2011) Mechanisms of blast induced brain injuries, experimental studies in rats. Neurolmage 54(Suppl 1):S89-S97

100. Rosa A, Ballarino M, Sorrentino A, Sthandier O, De Angelis FG, Marchioni M et al (2007) The interplay between the master transcription factor PU.1 and miR-424 regulates human monocyte/macrophage differentiation. Proc Natl Acad Sci U S A 104:19849-19854

101. Roy SK, Wachira SJ, Weihua X, Hu J, Kalvakolanu DV (2000) CCAAT/ enhancer-binding protein-beta regulates interferon-induced transcription through a novel element. J Biol Chem 275:12626-12632

102. Sagarkar S, Bhamburkar T, Shelkar G, Choudhary A, Kokare DM, Sakharkar AJ (2017) Minimal traumatic brain injury causes persistent changes in DNA methylation at BDNF gene promoters in rat amygdala: a possible role in anxiety-like behaviors. Neurobiol Dis 106:101-109

103. Salzmann MM (1965) A controlled trial with trimipramine, a new antidepressant drug. Br J Psychiatry 111:1105-1106

104. Samal BB, Waites CK, Almeida-Suhett C, Li Z, Marini AM, Samal NR et al (2015) Acute response of the hippocampal transcriptome following mild traumatic brain injury after controlled cortical impact in the rat. J Mol Neurosci 57:282-303

105. Sandhir R, Berman NEJ (2010) Age-dependent response of CCAAT/enhancer binding proteins following traumatic brain injury in mice. Neurochem Int 56:188-193

106. Schober ME, Ke X, Xing B, Block BP, Requena DF, McKnight R et al (2012) Traumatic brain injury increased IGF-1B mRNA and altered IGF-1 exon 5 and promoter region epigenetic characteristics in the rat pup hippocampus. J Neurotrauma 29:2075-2085

107. Scholar EM. xPharm: The Comprehensive Pharmacology Reference. Elsevier Inc. 2015. https://doi.org/10.1016/B978-008055232-3.62712-6. https://www. sciencedirect.com/science/article/pii/B9780080552323627126

108. Shannon P, Markiel A, Ozier O, Baliga NS, Wang JT, Ramage D et al (2003) Cytoscape: a software environment for integrated models of biomolecular interaction networks. Genome Res 13:2498-2504

109. Shin SS, Bray ER, Zhang CQ, Dixon CE (2011) Traumatic brain injury reduces striatal tyrosine hydroxylase activity and potassium-evoked dopamine release in rats. Brain Res 1369:208-215

110. Simon DW, McGeachy MJ, Bayır H, Clark RSB, Loane DJ, Kochanek PM (2017) The far-reaching scope of neuroinflammation after traumatic brain injury. Nat Rev Neurol 13:171-191

111. Smith AM, Gibbons HM, Oldfield RL, Bergin PM, Mee EW, Faull RLM et al (2013) The transcription factor PU.1 is critical for viability and function of human brain microglia. Glia 61:929-942

112. Smith DH, Chen XH, Pierce JE, Wolf J a, Trojanowski JQ, Graham DI et al (1997) Progressive atrophy and neuron death for one year following brain trauma in the rat. J Neurotrauma 14:715-727

113. Soltani Z, Khaksari M, Jafari E, Iranpour M, Shahrokhi N (2015) Is genistein neuroprotective in traumatic brain injury? Physiol Behav 152:26-31

114. Sommer N, Löschmann PA, Northoff GH, Weller M, Steinbrecher A, Steinbach JP et al (1995) The antidepressant rolipram suppresses cytokine production and prevents autoimmune encephalomyelitis. Nat Med 1:244-248

115. Statham AL, Strbenac D, Coolen MW, Stirzaker C, Clark SJ, Robinson MD (2010) Repitools: an R package for the analysis of enrichment-based epigenomic data. Bioinformatics 26:1662-1663

116. Subramanian A, Tamayo P, Mootha VK, Mukherjee S, Ebert BL, Gillette MA et al (2005) Gene set enrichment analysis: a knowledge-based approach for interpreting genome-wide expression profiles. Proc Natl Acad Sci U S A 102: 15545-15550

117. Sukumari-Ramesh S, Alleyne CH, Dhandapani KM (2016) The histone deacetylase inhibitor Suberoylanilide Hydroxamic acid (SAHA) confers acute neuroprotection after intracerebral hemorrhage in mice. Transl Stroke Res 7:141-148

118. Sy L-K, Yan S-C, Lok C-N, Man RYK, Che C-M (2008) Timosaponin A-III induces autophagy preceding mitochondria-mediated apoptosis in HeLa cancer cells. Cancer Res 68:10229-10237

119. Thomas MG, Welch C, Stone L, Allan P, Barker RA, White RB (2016) PAX6 expression may be protective against dopaminergic cell loss in Parkinson's disease. CNS Neurol Disord Drug Targets 15:73-79
120. Tien L-T, Lee Y-J, Pang Y, Lu S, Lee JW, Tseng C-H et al (2017) Neuroprotective effects of intranasal IGF-1 against neonatal lipopolysaccharide-induced neurobehavioral deficits and neuronal inflammation in the substantia Nigra and locus Coeruleus of juvenile rats. Dev Neurosci 39:443-459

121. Tsai Y-T, Wang C-C, Leung P-O, Lin K-C, Chio C-C, Hu C-Y et al (2014) Extracellular signal-regulated kinase $1 / 2$ is involved in a tamoxifen neuroprotective effect in a lateral fluid percussion injury rat model. J Surg Res 189:106-116

122. Valiyaveettil M, Alamneh YA, Miller S-A, Hammamieh R, Arun P, Wang Y et al (2013) Modulation of cholinergic pathways and inflammatory mediators in blast-induced traumatic brain injury. Chem Biol Interact 203:371-375

123. von Gertten C, Flores Morales A, Holmin S, Mathiesen T, Nordqvist A-CS (2005) Genomic responses in rat cerebral cortex after traumatic brain injury. BMC Neurosci 6:69

124. von Gertten C, Morales A, Holmin S, Mathiesen T, Nordqvist A-C, Ray S et al (2005) Genomic responses in rat cerebral cortex after traumatic brain injury. BMC Neurosci 6:69

125. Vonder Haar C, Anderson GD, Elmore BE, Moore LH, Wright AM, Kantor ED et al (2014) Comparison of the effect of minocycline and simvastatin on functional recovery and gene expression in a rat traumatic brain injury model. J Neurotrauma 31:961-975

126. Walton MR, Gibbons H, MacGibbon GA, Sirimanne E, Saura J, Gluckman PD et al (2000) PU.1 expression in microglia. J. Neuroimmunol 104:109-115

127. Wang L, Fu X, Peng X, Xiao Z, Li Z, Chen G et al (2016) DNA methylation profiling reveals correlation of differential methylation patterns with gene expression in human epilepsy. J Mol Neurosci 59:68-77

128. White TE, Ford GD, Surles-Zeigler MC, Gates AS, Laplaca MC, Ford BD (2013) Gene expression patterns following unilateral traumatic brain injury reveals a local pro-inflammatory and remote anti-inflammatory response. BMC Genomics 14:282

129. White TE, Surles-Zeigler MC, Ford GD, Gates AS, Davids B, Distel T et al (2016) Bilateral gene interaction hierarchy analysis of the cell death gene response emphasizes the significance of cell cycle genes following unilateral traumatic brain injury. BMC Genomics 17:130

130. Wong Y-H, Wu C-C, Wu JC-C, Lai H-Y, Chen K-Y, Jheng B-R et al. (2016) Temporal genetic modifications after controlled cortical impactunderstanding traumatic brain injury through a systematic network approach. Int J Mol Sci 17:216.

131. Wu J, Song R, Song W, Li Y, Zhang Q, Chen Y et al (2011) Chlorpromazine protects against apoptosis induced by exogenous stimuli in the developing rat brain. Burne T, editor. PLoS One 6:e21966

132. Xuan A, Long D, Li J, Ji W, Hong L, Zhang M et al (2012) Neuroprotective effects of valproic acid following transient global ischemia in rats. Life Sci 90:463-468

133. Yang K, Mu XS, Xue JJ, Whitson J, Salminen A, Dixon CE et al (1994) Increased expression of c-fos mRNA and AP-1 transcription factors after cortical impact injury in rats. Brain Res 664:141-147

134. Yoneda T, Lyall RM, Alsina MM, Persons PE, Spada AP, Levitzki A et al. (1991) The Antiproliferative effects of tyrosine kinase inhibitors Tyrphostins on a human squamous cell carcinoma in vitro and in nude mice. Cancer Res 51: 4430-4435.

135. Zakrzeska A, Schlicker E, Baranowska M, Kozłowska H, Kwolek G, Malinowska B (2010) A cannabinoid receptor, sensitive to O-1918, is involved in the delayed hypotension induced by anandamide in anaesthetized rats. $\mathrm{Br} J$ Pharmacol 160:574-584

136. Zhang X-Y, Gu C-G, Gu J-W, Zhang J-H, Zhu H, Zhang Y-C et al (2014) Analysis of key genes and modules during the courses of traumatic brain injury with microarray technology. Genet Mol Res Brazil 13:9220-9228 